\title{
Metabolic labeling of RNA uncovers the contribution of transcription and decay rates on hypoxia-induced changes in RNA levels
}

\author{
MARIA TIANA, ${ }^{1,2,3,7}$ BÁRBARA ACOSTA-IBORRA, ${ }^{1}$ ROSANA HERNÁNDEZ, ${ }^{1}$ CLARA GALIANA, ${ }^{1}$ \\ MIGUEL ÁNGEL FERNÁNDEZ-MORENO, ${ }^{1,4,5}$ BENILDE JIMENEZ, ${ }^{1,2,3}$ and LUIS DEL PESO ${ }^{1,2,3,6}$ \\ 1Departamento de Bioquímica, Universidad Autónoma de Madrid (UAM) and Instituto de Investigaciones Biomédicas "Alberto Sols" \\ (CSIC-UAM), 28029 Madrid, Spain \\ ${ }^{2}$ IdiPaz, Instituto de Investigación Sanitaria del Hospital Universitario La Paz, 28029 Madrid, Spain \\ ${ }^{3}$ CIBER de Enfermedades Respiratorias (CIBERES), Instituto de Salud Carlos III, 28029 Madrid, Spain \\ ${ }^{4}$ Centro de Investigación Biomédica en Red en Enfermedades Raras (CIBERER). Facultad de Medicina, Universidad Autónoma de Madrid, \\ Madrid 28029, Spain \\ ${ }^{5}$ Instituto de Investigación Sanitaria Hospital 12 de Octubre (imas12), Madrid 28041, Spain \\ ${ }^{6}$ Unidad Asociada de Biomedicina CSIC-UCLM, 02006, Albacete, Spain
}

\begin{abstract}
Cells adapt to environmental changes, including fluctuations in oxygen levels, through the induction of specific gene expression programs. However, most transcriptomic studies do not distinguish the relative contribution of transcription, RNA processing, and RNA degradation processes to cellular homeostasis. Here we used metabolic labeling followed by massive parallel sequencing of newly transcribed and preexisting RNA fractions to simultaneously analyze RNA synthesis and decay in primary endothelial cells exposed to low oxygen tension. We found that changes in transcription rates induced by hypoxia are the major determinant of changes in RNA levels. However, degradation rates also had a significant contribution, accounting for $24 \%$ of the observed variability in total mRNA. In addition, our results indicated that hypoxia led to a reduction of the overall mRNA stability from a median half-life in normoxia of $8.7 \mathrm{~h}$, to $5.7 \mathrm{~h}$ in hypoxia. Analysis of RNA content per cell confirmed a decrease of both mRNA and total RNA in hypoxic samples and that this effect is dependent on the EGLN/HIF/TSC2 axis. This effect could potentially contribute to fundamental global responses such as inhibition of translation in hypoxia. In summary, our study provides a quantitative analysis of the contribution of RNA synthesis and stability to the transcriptional response to hypoxia and uncovers an unexpected effect on the latter.
\end{abstract}

Keywords: hypoxia; RNA decay; transcription; HIF

\section{INTRODUCTION}

Eukaryotic cells show a remarkable regulatory flexibility that allows them to adjust to a constantly varying environment. Modulation of gene expression, consequence of changes at the transcriptional and post-transcriptional levels, plays a central role in the adaptation to environmental changes and stresses. However, quantitative information about the relative contribution of transcription to the changes in gene expression in response to specific signals is still scarce.

The response to hypoxia, defined as the situation where oxygen consumption exceeds its supply, is a paradigmatic

\footnotetext{
${ }^{7}$ Present address: CNIC- Spanish Center for Cardiovascular Research, Instituto de Salud Carlos III, Madrid, Spain

Corresponding authors: mtiana@cnic.es, Ipeso@iib.uam.es

Article is online at http://www.rnajournal.org/cgi/doi/10.1261/rna. 072611.119.
}

example of how gene expression shapes cell physiology to cope with environmental fluctuations. The hypoxia inducible factors (HIFs) are transcription factors that play a fundamental role in this response. HIF is a heterodimeric transcription factor conserved in all metazoans (lyer et al. 1998) that is composed of an oxygen-regulated alpha subunit (HIF $\alpha$ ) and a constitutive expressed beta subunit (HIF $\beta$ ) also known as aryl hydrocarbon receptor nuclear translocator (ARNT). There are three genes encoding HIF $\alpha$ subunits: HIF1A, EPAS1 (also known as HIF2A), and HIF3A. All these proteins belong to the PER-ARNT-SIM (PAS) subfamily of the basic helix-loop-helix (bHLH) family of transcription

(C) 2020 Tiana et al. This article is distributed exclusively by the RNA Society for the first 12 months after the full-issue publication date (see http://rnajournal.cshlp.org/site/misc/terms.xhtml). After 12 months, it is available under a Creative Commons License (Attribution-NonCommercial 4.0 International), as described at http:// creativecommons.org/licenses/by-nc/4.0/. 
factors and they have a similar domain organization. HIF $\alpha$ and HIF $\beta$ subunits share an amino terminus bHLH domain that mediates the DNA binding and a central region or PAS domain that facilitates the heterodimerization (Jiang et al. 1997). Only the $\alpha$ subunits contain an oxygen dependent degradation domain (ODD) with proline residues (Pro 402/Pro 564 in HIF1A, Pro 405/Pro 531 in EPAS1, and pro 492 in HIF3A) that are essential for the oxygen-induced HIF stabilization. Furthermore, HIF1A and EPAS1 present two transactivation domains NTAD and CTAD that can bind transcriptional coregulators such as CBP/p300 and the cyclin dependent kinase 8 (CDK8) (Arany et al. 1996; Kasper et al. 2005; Galbraith et al. 2013; Choudhry et al. 2014; Dengler et al. 2014). The regulation of HIF $\alpha$ stability is mediated by a family of enzymes called EGL-nine homologs (EGLNs) that, in normoxic conditions, use molecular oxygen to hydroxylate specific proline residues in HIF $\alpha$. The hydroxylation in one of these residues is sufficient for the recognition of HIF $\alpha$ by the von Hippel-Lindau tumor suppressor protein $(\mathrm{pVHL})$ that is the substrate recognition subunit of an E3-ubiquitin ligase complex. Thus, pVHL binding leads to HIF $\alpha$ ubiquitination, targeting it for degradation via proteasome (Maxwell et al. 1999; Ivan et al. 2001; Jaakkola et al. 2001). In hypoxic conditions, HIF is stabilized and binds the RCGTG motif present in the regulatory regions of its targets genes and interacts with the transcriptional machinery to regulate their transcription.

The global gene expression pattern induced by hypoxia has been widely studied (Hu et al. 2003; Scheurer et al. 2004; Elvidge et al. 2006; Warnecke et al. 2008; Xia and Kung 2009; Mimura et al. 2012; Weigand et al. 2012; Salama et al. 2015; Galbraith et al. 2017; Chen et al. 2018; Moreau et al. 2018; Chakraborty et al. 2019; Smythies et al. 2019). However, these studies relied on RNA-seq and microarrays that detect mRNA steady state levels and therefore cannot distinguish between regulation of transcription and other mechanisms of post-transcriptional regulation. In this regard, apart from transcription, other processes such as RNA maturation and decay are under an exhaustive control and contribute to changes in gene expression. The relative importance of each process to determine the steady state expression levels of proteins has been studied in a few cellular systems, including the determination of basal levels of expression in fibroblasts (Schwanhausser et al. 2011) and the response of dendritic cells to lipopolysaccharide (Rabani et al. 2011). The conclusion of these and related studies is that transcription rate explains most of the observed variability in gene expression (Rabani et al. 2011; Schwanhausser et al. 2011, 2013; $\mathrm{Li}$ et al. 2014). However, the generality of this conclusion and more specifically, to which extent the transcriptional changes mediated by HIF affect mRNA expression changes observed under hypoxia, is unknown. In this regard, it has been demonstrated that in addition to transcription, regulation of half-life of certain mRNAs has fundamental roles in hypoxia. For instance, the mRNA level of vascular endothelial growth factor $A$ (VEGFA), a potent angiogenic factor, is regulated by hypoxia through both HIF-mediated transcriptional up-regulation, as well as HIF-independent post-transcriptional regulation. VEGFA mRNA is an unstable transcript with a short half-life (60-180 min) in normoxia. However, under hypoxia VEGFA mRNA is stabilized by the binding of different RNA-binding proteins, such as HuR or hRNP-L, to AU-rich elements (AREs) present in its 3'-UTR (Levy et al. 1996, 1998; Shih and Claffey 1999; GoldbergCohen et al. 2002). Other examples of transcripts whose half-lives are regulated by hypoxia through AREs include erythropoietin (EPO) (Goldberg et al. 1991; Rondon et al. 1991; Ho et al. 1995) and tyrosine hydroxylase (TH) mRNAs (Czyzyk-Krzeska et al. 1994). In addition, hypoxia has an important role in the regulation of miRNAs (Voellenkle et al. 2012; Nallamshetty et al. 2013; Camps et al. 2014), which in turn regulate mRNA stability and translation. Altogether, these results suggest a pervasive effect of hypoxia on mRNA stability, therefore, a global study of how hypoxia modulate mRNA half-life is needed to fully understand how cells adapt to low oxygen situations.

Herein, we determined the relative contribution of RNA transcription and stability to gene expression changes induced by hypoxia in primary human endothelial cells (human umbilical vein endothelial cells, HUVEC) that are central actors in the induction of angiogenesis, a key adaptation response to hypoxia. Our results show that de novo transcription explains $72 \%$ of gene expression changes observed upon exposure to low oxygen conditions, while halflife regulation underlies most of the remaining variability (24\%). In addition, we found that the EGLN/HIF/TSC2 axis increases global RNA decay rates, leading to a $30 \%$ reduction of cellular mRNA as well as rRNA content. Thus, our work reveals an unexpected role of hypoxia on global RNA stability and provides quantitative data to understand the effect of hypoxia on gene expression.

\section{RESULTS}

\section{Transcription rate is the major determinant of hypoxic mRNA levels}

The transcriptional response to hypoxia has been studied in many different model systems at the genome scale ( $\mathrm{Hu}$ et al. 2003; Scheurer et al. 2004; Elvidge et al. 2006; Warnecke et al. 2008; Xia and Kung 2009; Mimura et al. 2012; Weigand et al. 2012; Salama et al. 2015; Galbraith et al. 2017; Chen et al. 2018; Moreau et al. 2018; Chakraborty et al. 2019; Smythies et al. 2019). However, in all these works mRNA levels were determined by means of RNA-sequencing or microarrays and hence they could only assess the effect of hypoxia on steady state mRNA levels, which are determined by the combination of the relative rates of transcription and decay. Aiming to determine 
the contribution of these two processes in the response to hypoxia, we pulse-treated HUVEC for $2 \mathrm{~h}$ with 4-thiouridine $(4 s U)$ to label nascent RNA and then characterized the pattern of newly transcribed mRNAs by affinity capture of the labeled transcripts followed by high-throughput sequencing (Fig. 1A). Incorporation of $4 \mathrm{sU}$ into mRNA after a short pulse can be used as a proxy for transcription rate and comparison of changes in this nascent fraction to those in total mRNA levels allows quantification of the role of mRNA stability on gene expression (Dolken et al. 2008; Schwanhausser et al. 2011). Hence, to determine the contribution of transcription to gene expression, we compared expression changes induced by hypoxia in the total mRNA fraction to those observed in the newly synthesized fractions (Fig. 1A). As shown in Figure 1B, taking a relatively relaxed threshold of FDR $<0.05$, only about one third of the genes found differentially expressed in the total mRNA- fraction showed altered transcription (27\% and $35 \%$ of the down- and up-regulated genes, respectively). However, this percentage gradually increased up to $\sim 70 \%$ in both fractions when, in addition to the FDR, we used increasingly restrictive fold-change thresholds to consider genes as differentially expressed in hypoxia (Fig. 1C). This result suggests that transcription is mostly responsible for large expression changes in the total mRNA fraction, whereas changes of small magnitude are likely due to variations of mRNA half-lives. In addition, we observed a significant positive linear correlation between changes in gene expression observed in total and newly transcribed mRNA fractions (Fig. 1D). By focusing on genes whose expression was significantly altered by hypoxia (FDR $<0.01)$ in either total or newly transcribed mRNA fractions, we found that the transcriptional component (changes in newly synthesized mRNA) accounted for $72 \%$ of the observed
A

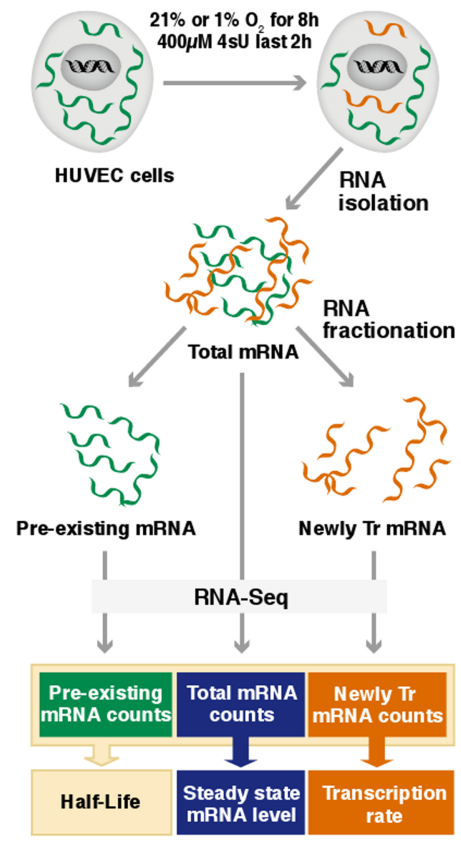

B

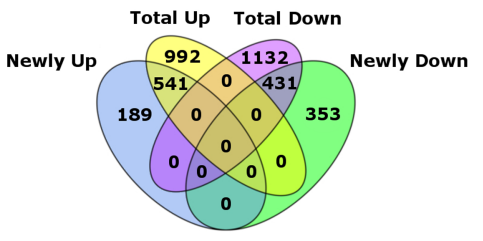

C

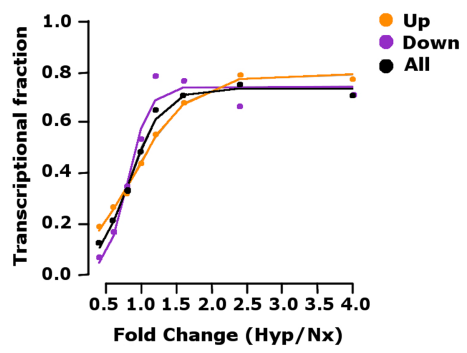

D

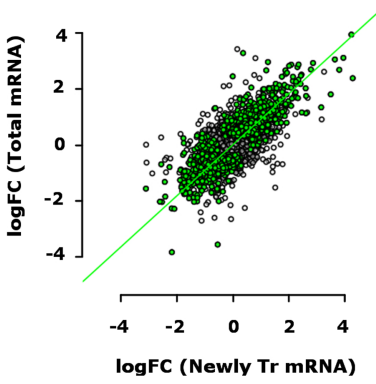

FIGURE 1. Hypoxia-induced changes in gene expression are predominantly controlled at the level of transcription. (A) Schematic diagram depicting the experimental procedure and the information provided by each RNA fraction. (B) Venn diagrams showing the overlap between the genes found differentially overexpressed (FDR $<0.05)$ in the total (Total Up) and newly transcribed (Newly Up) fractions and the differentially down-regulated (FDR $<0.05)$ in the total (Total Down) and newly transcribed (Newly Down) fractions. $(C)$ The graph represents the proportion of genes in the total mRNA fraction that were also differentially expressed in the newly transcribed fraction for: all regulated genes (black line), significantly down-regulated genes (purple line), and significantly up-regulated genes (orange line). Genes were considered differentially expressed if, in addition to being significantly regulated (FDR < 0.05), showed an absolute value of induction above the indicated threshold of $\log F_{C}$ ( $x$-axis). The magnitude of change induced by hypoxia was calculated for each gene as the absolute value of the logarithm of the ratio of the expression level in normoxia over hypoxia $\left(\log \mathrm{F}_{C}\right)$. (D) The magnitude of change $\left(\log _{2}\right.$-fold change, log $\left.\mathrm{F}_{\mathrm{C}}\right)$ induced by hypoxia in $4 \mathrm{~s} U$-labeled genes ("Newly tr mRNA") was represented against the changes in the total mRNA fraction ("Total mRNA"). Genes significantly (FDR < 0.01) regulated by hypoxia in either fraction are labeled in green. Regression analysis of significantly regulated genes showed that total mRNA level increased significantly with transcription $\left(F_{(1,2225)}=5756, P\right.$-value $\left.<<0.01\right)$. 
variability in total mRNA (regression analysis, $F_{(1,2225)}=$ $\left.5756, P<10^{-16}, R^{2} 225=0.7212\right)$. In sum, these results suggest that transcriptional mechanisms largely determine gene expression changes in hypoxia.

\section{RNA stability is significantly affected by hypoxia}

In spite of the major role of transcription, this process cannot explain around $28 \%$ of the variability in total mRNA levels. To further explore the contribution of nontranscriptional processes, we investigated the effect of hypoxia on mRNA half-lives by sequencing newly synthesized mRNA (4sU-labeled) in parallel with preexisting (nonlabeled) and total mRNA factions from the same RNA sample (Fig. 1A). This analysis allowed us to determine individual mRNA half-lives under normoxia and hypoxia (Supplemental Table S1; Dolken et al. 2008; Schwanhausser et al. 2011). First of all, we compared the half-lives values obtained in our analysis with the half-lives values determined for mouse-fibroblasts (NIH3T3) by the same technique in two independent works (Dolken et al. 2008; Schwanhausser et al. 2011). We found that the distribution of the half-lives of normoxic and hypoxic HUVEC mRNAs (median half-life of 8.7 and $5,7 \mathrm{~h}$, respectively) fell between the range of the mRNA half-lives determined by Dolken et al. and Schwanhausser et al. (median half-life of 5 and $9 \mathrm{~h}$, respectively), suggesting that our HUVEC determinations were comparable in magnitude to those reported for mouse fibroblasts (Fig. 2A). In addition, half-life of selected mRNAs were determined by measuring mRNA stability after inhibition of transcription by actinomycin D. For this analysis, mRNAs were selected according to the $4 \mathrm{sU}$ half-life determinations to include a wide representation of short-lived and medium-lived mRNAs (Supplemental Tables S1, S2). The mRNA half-life values estimated by this method were in good agreement with the values derived from the $4 \mathrm{sU}$ experiment (Fig. 2B; Pearson's $R_{48}=0.65, P<0.001$, linear regression $\left.R^{2}=0.77\right)$. Therefore, our determinations based on sequencing of the distinct mRNA fractions allowed for an accurate determination of mRNA half-lives. Next, we investigated whether hypoxia-induced changes on mRNA stability could account for the remaining variability in total mRNA levels that are not explained by transcription. A linear regression model including mRNA half-lives as an additional explanatory variable accounted for up to $96 \%$ of changes in total mRNA induced by hypoxia (multiple linear regression analysis, $F_{(2,1851)}=26110, P<0.0001$, adjusted $R^{2}{ }_{1851}=0.9658$ ). Thus, changes in mRNA half-life explain an additional $24 \%$ of the observed effects on gene expression and both variables, transcription and stability, jointly explain most of the variability in mRNA levels (Supplemental Movie S1).

In spite of its relatively minor role in the gene expression changes induced by hypoxia, the analysis of the effects of hypoxia on mRNA half-life revealed a modest but signifi- cant $(P<0.01$ paired $t$-test $)$ reduction of the overall mRNA stability, from a median half-life in normoxia of $8.7 \mathrm{~h}$ to a median half-life in hypoxia of $5.7 \mathrm{~h}$ (Fig. 2A,C). We confirmed this result by estimation of individual mRNA levels over time upon inhibition of transcription with actinomycin D under normoxia or hypoxia (Fig. 2D). For these analyses we selected a set of mRNAs whose changes in stability in response to hypoxia, according to half-lives determined in our $4 \mathrm{sU}$ analysis (Supplemental Tables S1, S2), varied in magnitude. This selection included those genes represented in Figure 2B. Although the vast majority of mRNAs showed reduced half-life under hypoxia, our analysis also identified a few transcripts that were stabilized. Notably, among the latter was VEGFA, a transcript known to be stabilized in hypoxia (Levy et al. 1996, 1998; Levy 1998; Shih and Claffey 1999; Goldberg-Cohen et al. 2002). The pervasive effect on mRNA decay rates, suggested a general mechanism of RNA degradation rather than a sequence-specific mechanism such as those mediated by miRNAs. Therefore, we explored if the effect of hypoxia on mRNA decay rates was also observed in unfractionated RNA; most of which consists in rRNA. With this objective, we pulse-labeled HUVEC cells with tritiated uridine and determined the decay of radioactive label in total RNA. As shown in Figure $2 \mathrm{E}$, the remaining radioactivity on total RNA after $16 \mathrm{~h}$ of culture was higher in normoxia than in hypoxia, suggesting increased rRNA decay rates in hypoxia. Thus, hypoxia induces a global decay in RNA, rather than a specific effect on protein coding genes.

In addition to increased decay, a general reduction on transcription rates could also potentially contribute to decreased RNA levels in hypoxic cells. However, we did not observe a decrease in $4 \mathrm{sU}$ incorporation in HUVEC cells exposed to $1 \%$ oxygen for $8 \mathrm{~h}$ compared to normoxic controls (Fig. 2F). In fact, mRNA synthesis was slightly increased in hypoxia, suggesting very similar global transcription rates in both situations. In agreement, determination of the quantity of the $47 \mathrm{~S}$ precursor ribosomal RNA (pre-RNA) after $16 \mathrm{~h}$ of hypoxic exposure, which correlates with the rate of rRNA transcription (Cui and Tseng 2004), did not show significant differences between normoxia and hypoxia (Fig. 2G).

In summary, these results suggest that hypoxia results in modest increase of mRNA and rRNA degradation and, although no global changes in transcription are detected (Fig. 2F,G), changes in transcription of specific mRNAs largely contributes to the observed changes in mRNA expression during hypoxia (Fig. 1D).

\section{Hypoxia-induced RNA decay is HIF-dependent}

The HIF axis is the best characterized signaling pathway in the response to hypoxia. Thus, as a first attempt to explore the molecular mechanism by which RNA degradation was 
A

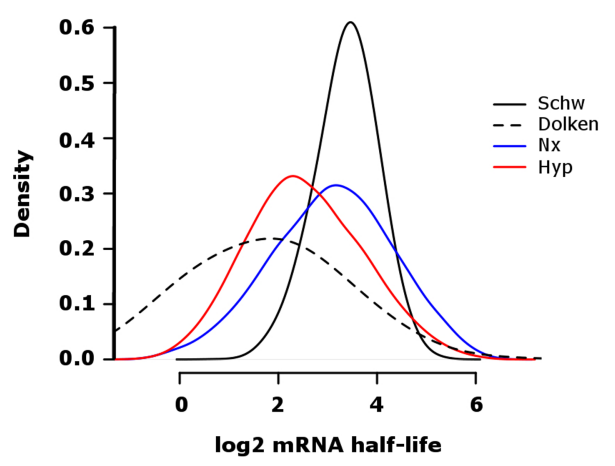

D

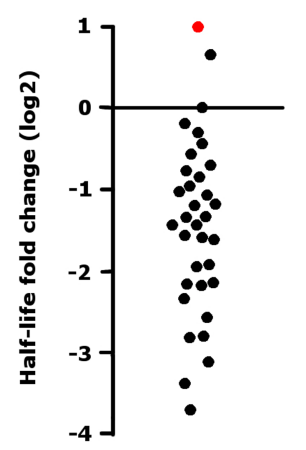

$\mathbf{E}$

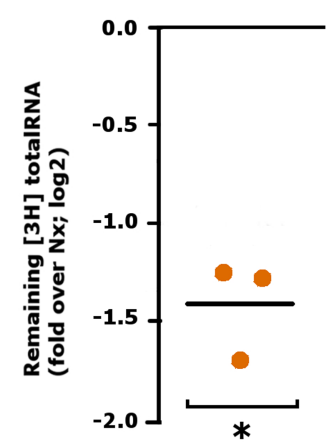

B

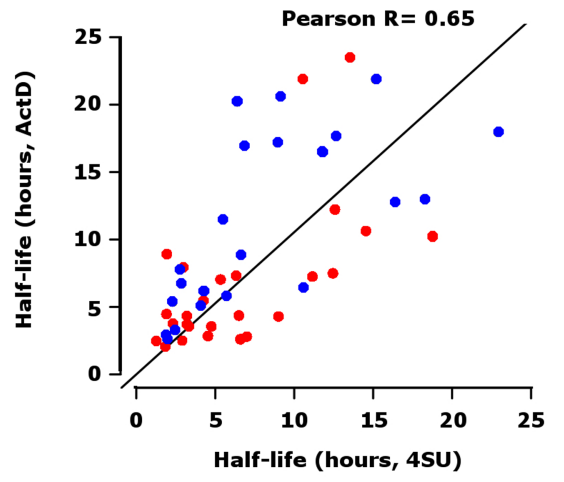

$\mathbf{F}$

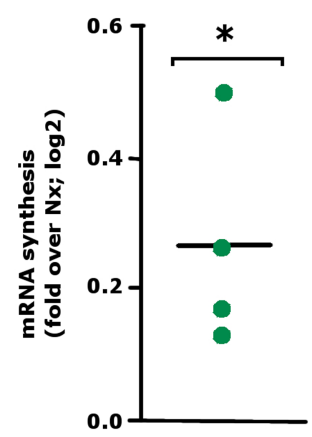

C

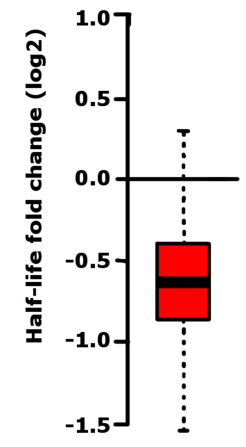

G

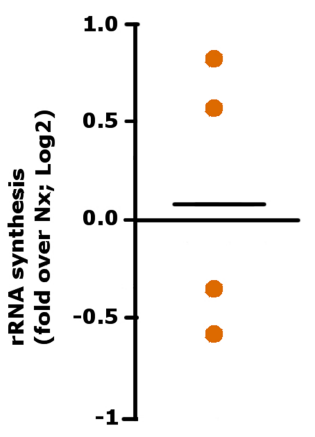

FIGURE 2. Decrease of mRNA and total RNA half-lives under hypoxic conditions. (A) Distribution of mRNA half-lives, determined by $4 \mathrm{~s} U$ pulselabeling as indicated in Materials and Methods, in normoxic (blue) and hypoxic (red) HUVEC. The values published in Dolken et al. (2008) (Dolken, dotted line) and (Schwanhausser et al. 2011) (Schw, black line) are overlapped for comparison. (B) Comparison of individual half-life values obtained by the high-resolution gene expression profiling experiment and the data derived from the determination of mRNA half-life upon inhibition of RNA-pol with actinomycin D. $\left(F_{(1,49)}=168, P<0.001\right.$, linear regression $\left.R^{2}=0.77\right)(C)$ Distribution of changes in decay rates induced by hypoxia, as determined in the high-resolution profiling experiments, represented as the logarithm of the ratio of the half-life in hypoxia over normoxia. (D) The graph represents the half-life of individual genes, calculated upon inhibition of RNA-pol with actinomycin D, in HUVEC cells in normoxia versus hypoxia as $\log _{2}$ of the ratio. Each dot represents the mean of three independent experiments. The red dot represents VEGFA. (E) Pulse-labeling of total RNA determined in HUVEC. The graph represents the logarithm of the ratio of the hypoxic (16 h) remaining radioactivity normalized by normoxic values. The comparison of the observed ratios was significantly higher than expected from a sample with a mean log ${ }_{2}$-ratio of 0 (single sample Student's t-test, $P$-value $=0.0122)$. $(F)$ The amount of mRNA in the newly synthesized mRNA fraction (4sU-labeled) from the experiment described in Figure 1A was determined by spectrophotometry and represented as the $\log _{2}$ of the ratio of the values obtained in hypoxia over normoxia. Each point represents data from an independent experiment. The comparison of the observed ratios was significantly higher than expected from a sample with a mean $\log _{2}$-ratio of 0 (single sample Student's $t$-test, $P$-value $=0.049$ ). (G) $47 \mathrm{~S}$ rRNA precursor levels were determined by RT-qPCR in cells exposed overnight to normoxia or hypoxia and values normalized to $28 \mathrm{~S}$ rRNA content. Each dot represents the ratio hypoxia over normoxia in an independent experiment. The observed ratios were not significantly different to the expected value of 0 (single sample Student's t-test, $P=0.8185$ ).

increased in hypoxia, we investigated the effect of EGLN inhibitor Dimethyloxalylglycine (DMOG) on total RNA mass. The EGLN family of enzymes acts as cellular oxygen sensors and functions as the most apical elements of the HIF axis suppressing its activity in the presence of oxygen, thus DMOG prevents HIF $\alpha$ degradation in normoxia. As is shown in Figure 3A, mRNA content was reduced in hypoxic conditions as well as in DMOG-treated cells compared with normoxia. Since HIF is the major target of EGLNs and a key player in the response to hypoxia, we next examined its involvement in this process by silencing the constitutive ARNT subunit. ARNT knockdown resulted in 36\%$15 \%$ of control ARNT expression values and blocked the induction of the HIF target EGLN3 (Fig. 3B,C). Additionally, we performed an ARNT western blot to confirm ARNT silencing (Fig. 3D). Importantly, ARNT knockdown significantly attenuated the RNA decay promoted by hypoxia (Fig. 3E), suggesting that HIF activity is necessary in this process. To further address the involvement of HIFs, we silenced HIF1A or EPAS1 expression to $30 \%-35 \%$ and $30 \%-15 \%$ of their control levels, respectively (Fig. 3FH). Then, silenced and control HUVEC were pulse-labeled with tritiated uridine and exposed to normoxia or hypoxia for $16 \mathrm{~h}$. After measuring the radioactivity present in total RNA, we observed that silencing of HIF1A or EPAS1 partially prevent RNA decay (Fig. 3I). 
A

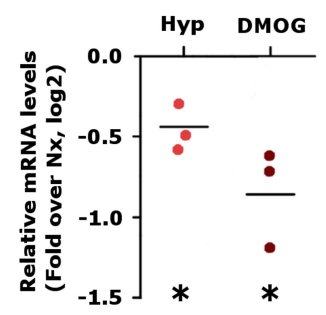

E

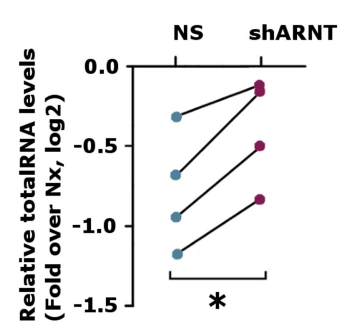

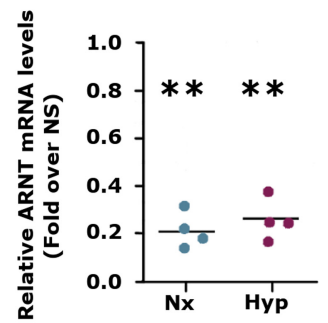

F

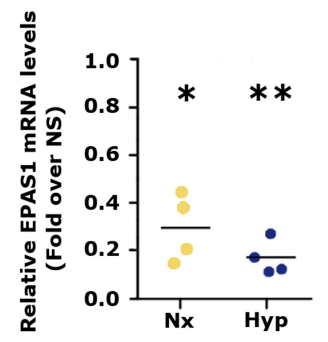

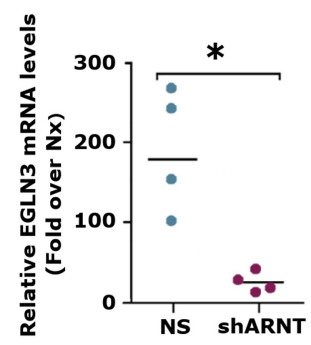

G

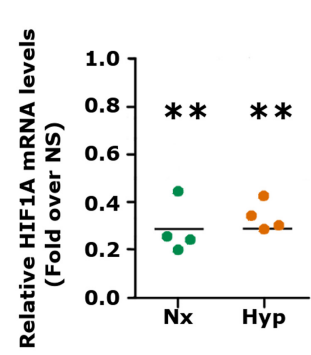

D

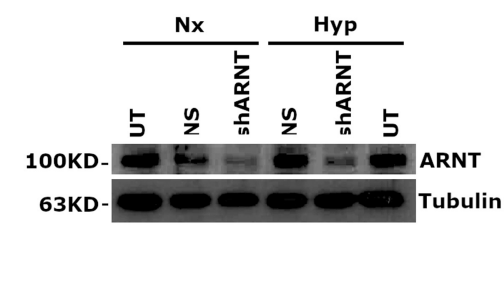

H

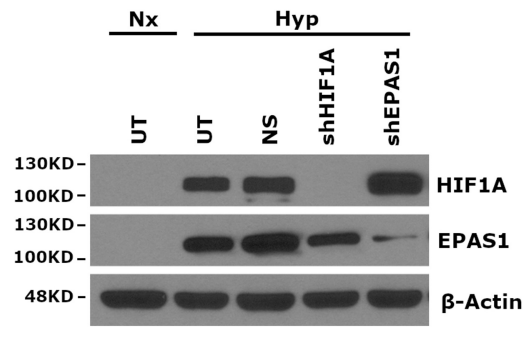

K

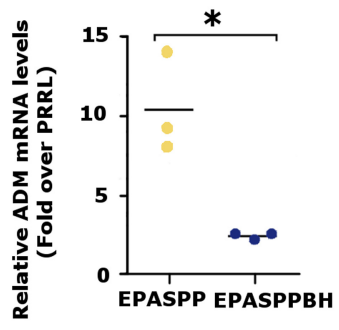

N

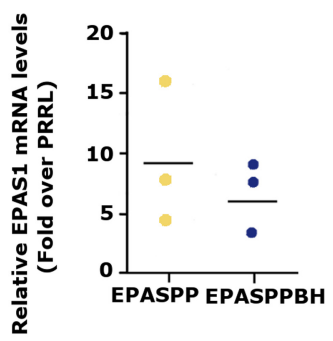

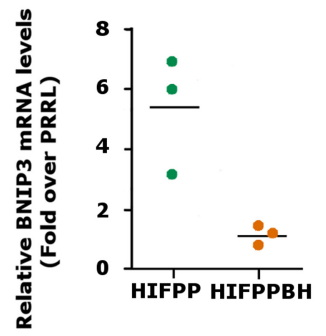

0

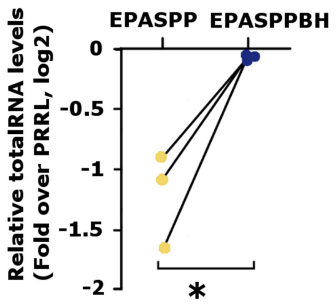

M

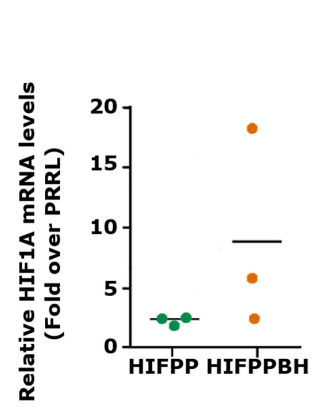

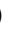

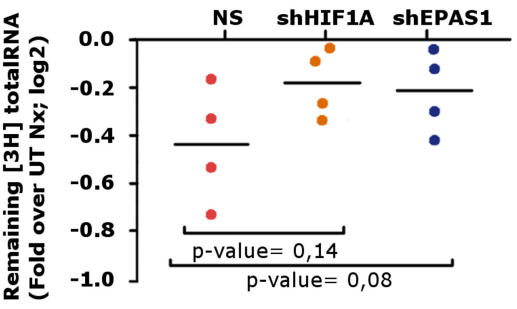

L

$\mathbf{P}$

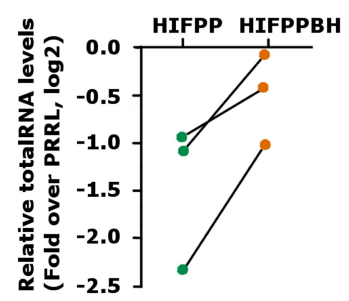

Q

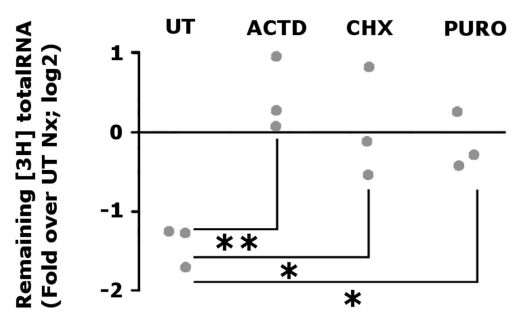

FIGURE 3. (Legend on next page) 
To analyze if HIF stabilization was sufficient to promote RNA degradation, we infected HUVEC with lentiviral vectors that overexpressed constitutively active forms of EPAS1 (EPASPP) or HIF1A (HIFPP) that had their oxygensensitive prolines residues substituted by alanine to prevent hydroxylation, rendering these isoforms constitutively active even in normoxia (Kondo et al. 2002). Additionally, we included mutant versions of these constructs whose bHLH motif was altered to prevent their capacity to bind DNA (EPASPPBH, HIFPPBH) (Kondo et al. 2002). As expected, the expression of EPASPP in normoxia resulted in a strong induction of ADM mRNA, a EPAS1-target gene, whereas the expression of EPASPPBH had no effect
(Fig. 3J,K). Similarly, the HIF1A-target BNIP3 was strongly induced by overexpression of HIF1PP with intact bHLH domain (Fig. 3L,M). We also analyzed by western blot the HIFPP/HIFPPBH and EPASPP/EPASPPBH overexpression (Fig. $3 \mathrm{~N}$ ). As is shown in Figure 3O,P, transduction of the constitutively active forms of both EPAS1 and HIF1A decreased RNA content per cell in normoxia. In contrast, the overexpression of the mutants lacking a functional DNA binding motif did not reduce RNA content. Therefore, these results suggest that HIF transcriptional activity is necessary and sufficient to induce RNA decay. Furthermore, the dependency on an intact bHLH domain suggested that the increased decay rate might be

FIGURE 3. Hypoxia-induced mRNA decay is HIF-dependent. (A) mRNA content per cell from cells grown for $16 \mathrm{~h}$ in normoxia, hypoxia (Hyp) or DMOG (DMOG). Each dot represents the ratio of mRNA levels in hypoxia or DMOG over normoxia in an independent experiment. The observed ratios were significantly lower than expected from a sample with a mean ratio of 1 (single sample Student's t-test, $P$-value $=0.033$ and $P$-value $=$ 0.041 , respectively). (B) ARNT mRNA levels in HUVEC cells transduced with lentiviral particles expressing a shRNA to silence ARNT expression versus control (NS). The ARNT expression was on average $21 \%$ and $25 \%$ of that in control cells in normoxia and hypoxia, respectively, and significantly different to the expected value of 1 (single sample Student's $t$-test, $P=0.006$ and $P=0.007$ for cells under normoxia and hypoxia, respectively). (C) EGLN3 mRNA levels in HUVEC cells transduced with lentiviral particles expressing a shRNA to silence ARNT expression versus control (NS). The effect of hypoxia on EGLN3 induction was significantly attenuated in ARNT knockdown cells ( $P$-value $=0.017$; paired Student's $t$-test). (D) HUVEC cells transduced with lentiviral particles expressing a shRNA to silence ARNT (shARNT) or a control shRNA (NS) or mock infected (UT) were exposed to normoxia (Nx) or hypoxia (Hyp) for $16 \mathrm{~h}$. The level of ARNT protein and tubulin were determined by immunoblot. (E) Ratio of hypoxic versus normoxic total RNA content per cell from control cells (NS) and cells whose ARNT expression was silenced (shARNT). Each dot represents a determination from a single experiment and matched observations (derived from the same experiment) are represented joined by a line. The effect of hypoxia on RNA level was significantly attenuated in ARNT knockdown cells ( $P$-value $=0.014$; paired Student's t-test). ( $F$ ) EPAS1 mRNA levels in HUVEC cells transduced with lentiviral particles expressing a shRNA to silence EPAS1 expression versus control (NS). EPAS1 expression was on average $30 \%$ and $15 \%$ of that in control cells in normoxia and hypoxia, respectively, and significantly different to the expected value of 1 (single sample Student's t-test, $P=0.0021$ and $P=0.0002$ for cells under normoxia and hypoxia, respectively). (G) HIF1A mRNA levels in HUVEC cells transduced with lentiviral particles expressing a shRNA to silence HIF1A expression versus control (NS). HIF1A expression was on average $30 \%$ and $35 \%$ of that in control cells in normoxia and hypoxia, respectively and significantly different to the expected value of 1 (single sample Student's t-test, $P=0.0009$ and $P=0.0002$ for cells under normoxia and hypoxia, respectively). $(H)$ HUVEC cells transduced with lentiviral particles expressing a shRNA to silence HIF1A (shHIF1A), EPAS1 (shEPAS1) or a control shRNA (NS) or mock infected (UT) were exposed to normoxia (Nx) or hypoxia (Hyp) for $16 \mathrm{~h}$. The levels of HIF1A, EPAS1 and $\beta$-actin were determined by immunoblot. (I) Pulse-labeling of total RNA determined in control HUVEC cells (NS) and cells whose HIF1A or EPAS1 expression was silenced (shHIF1A and shEPAS1). The graph represents the logarithm of the ratio of the hypoxic $(16 \mathrm{~h})$ remaining radioactivity normalized by normoxic values. Each dot represents a determination from a single experiment. The effect of hypoxia on RNA level showed clear tendency to be attenuated in shHIF1A and shEPAS1 but did not reach statistical significance (shHIF1A $P=0.14$; paired Student's $t$-test; shEPAS1 $P=0.08$; paired Student's $t$-test). $(J)$ EPAS1 mRNA levels of HUVEC cells transduced with a constitutively stable form of EPAS1 (EPASPP) or a stable but transcriptionally inactive form (EPASPPBH) compared with the control (PRRL). The expression of mutant forms of EPAS1 was similar ( $P=0.43$, paired Student's $t$-test). (K) ADM mRNA levels of HUVEC cells transduced with a constitutively stable form of EPAS1 (EPASPP) or a stable but transcriptionally inactive form (EPASPPBH) compared with the control (PRRL). The effect of EPASPP on ADM expression was significantly higher than that of EPASPPBH ( $P=0.023$, paired Student's $t$-test). ( $L$ ) HIF1A mRNA levels of HUVEC cells transduced with a constitutively stable form of HIF1A (HIFPP) or a stable but transcriptionally inactive form (HIFPPBH) compared with the control (PRRL). The expression of HIFPPBH was higher than that of HIFPP but the difference did not reached statistical significance $(P=0.34$, paired Student's t-test). (M) BNIP3 mRNA levels of HUVEC cells transduced with a constitutively stable form of HIF1A (HIFPP) or a stable but transcriptionally inactive form (HIFPPBH) compared with the control (PRRL). The effect of HIFPP on BNIP3 expression was higher than that of HIFPPBH, but the difference did not reached statistical significance $(P=0.079$, paired Student's $t$-test). $(N)$ Western blot to determine the overexpression of the HIFPP, HIFPPBH, EPASPP, EPASPP, or empty vector (PRRL) in samples in normoxia (Nx) or hypoxia (Hyp) for 16 h. $(O, P)$ Ratio of hypoxic versus normoxic total RNA content per cell in HUVEC cells overexpressing a constitutively active EPAS1 (EPASPP) or HIF1A (HIFPP) and a constitutively active EPAS1 or HIF1A whose bHLH motive has been mutated (EPASPPBH, HIFPPBH). Each dot represents a determination from a single experiment and matched observations (derived from the same experiment) are represented joined by a line. The expression of EPASPP resulted in RNA level significantly reduced as compared to control cells, $(P$-value $=0.025$, single sample Student's t-test) and the effect of each EPAS1 mutant on RNA level was significantly different ( $P$-value $=0.025$, paired Student's $t$-test). The expression of HIFPP resulted in RNA level reduced as compared to control cells, but did not reach statistical significance ( $P$-value $=0.08$, single sample Student's $t$-test) and the effect of each HIF mutant on RNA level was not significantly different ( $P$-value $=0.23$, paired Student's t-test). (Q) Ratio of remaining radioactivity present in hypoxic samples over normoxia in untreated cells (UT) and cells treated with actinomycin D (ACTD), cycloheximide (CHX) or puromycin (PURO) after pulse-labeling with tritiated uridine. Each dot represents a determination from a single experiment. A single factor ANOVA showed a significant difference among the four treatment groups UT, ACTD, CHX, and PURO $\left(F_{(3,8)}=8.487, P\right.$-value $\left.=0.007\right)$ and a posteriori Tukey test showed that all drug treatment means were significantly different than the control mean $(P$-value $=0.006, P$-value $=0.022$, and $P$-value $=0.047$ for ACTD, CHX, and PURO, respectively). 
mediated by a HIF-target(s). To test this possibility, HUVEC cells were pulsed during $2 \mathrm{~h}$ with tritiated uridine, and then treated with actinomycin (ACTD), cycloheximide (CHX) or puromycin (PURO) and exposed to hypoxia or normoxia for 8 additional hours. After these treatments, RNA was purified from samples and the remaining radioactivity was quantified by scintillation counting. As is shown in Figure 30 , inhibition of transcription with actinomycin D or inhibition of translation with cycloheximide or puromycin completely blocked RNA degradation in hypoxia. All these results suggest that a HIF target(s), whose transcription is induced by hypoxia, is responsible for the increased RNA decay rates.

\section{Inactivation of mTOR through TSC2 induces RNA decay in hypoxia}

It is well established that during hypoxia, the oxygendeprived cells diminish protein synthesis through the inhibition of multiple key regulators of translation, including elF2a and the mammalian target of rapamycin (mTOR), in an attempt to save energy (Liu et al. 2006; Wouters and Koritzinsky 2008). In addition, RNA stability is intimately coupled to translation (Garneau et al. 2007), therefore, it could be possible that the decreased RNA half-life observed in hypoxia was a consequence of blunted translation. To test this possibility, we first determined the effect of hypoxia on translation in HUVEC. To that end, we used the Click-iT Plus OPP Alexa Fluor 647 Protein Synthesis Assay Kit to detect protein synthesis in normoxic, DMOG-treated cells and cycloheximide-treated control cells. As is shown in Figure 4A, DMOG induces a significant decrease in the protein translational rates compared with normoxic cells. The effect of hypoxia and DMOG on protein synthesis was independently confirmed using metabolic pulse-labeling with 35S-Methionine (Fig. 4G). However, while silencing of ARNT prevented RNA decay (Fig. 3E), it had no effect on the inhibition of protein synthesis induced by DMOG (Fig. 4B,C), suggesting that RNA decay is not a mere consequence of blunted translation.

It has been described that hypoxia triggers HIF-dependent and independent mechanisms to suppress translation. Thus, some of the HIF-dependent pathways could be coupled to RNA degradation. One of the former mechanisms involves the TSC2-dependent inactivation of mTOR by the HIF-target REDD1, resulting in the inhibition of the cap-dependent translation (Brugarolas et al. 2004; Wouters and Koritzinsky 2008). In agreement, we observed decreased phosphorylation of the ribosomal protein S6 (rpS6), a direct target of the kinase mTOR, upon treatment with hypoxia (Fig. 4D) or DMOG (Fig. 4E). Accordingly, interference of EPAS1 prevented the suppression of mTOR activity by hypoxia in HUVEC (Fig. 4F). Thus, we next tested the effect of knocking down TSC2 expression on protein synthesis and RNA stability. Hypoxia still repressed protein synthesis in TSC2 silenced cells (Fig. 4G), in spite of efficient reduction of TSC2 expression to $11 \%-7 \%$ of the control levels (Fig. $4 \mathrm{H}$ ). Despite its lack of effect on translation, silencing of TSC2 significantly prevented RNA decay induced by hypoxia (Fig. 4I). Altogether, these results suggest that pathway EGLN/ HIF/TSC2 regulates RNA stability independently of its effect on protein synthesis.

\section{DISCUSSION}

In the present work, we aimed to achieve a comprehensive and quantitative understanding of the gene expression changes that occur under adaptation of primary endothelial cells to hypoxic conditions. Previous studies focused on the analysis of the steady state mRNA levels, which are dictated by transcription and decay rates. Thus, we used a metabolic-labeling strategy to study the relative contribution of these processes on mRNA levels in response to hypoxia. In agreement with previous results on general mRNA regulation (Dolken et al. 2008; Rabani et al. 2011; Schwanhausser et al. 2011), we found that, although the relative contribution of transcription and decay rates is different for each individual gene, on average, transcription plays a dominant role on the changes induced by hypoxia in total mRNA fraction (Fig. 1D). Specifically, hypoxia-induced changes in transcription rates explain up to $72 \%$ of the variability in total mRNA levels. Moreover, the fraction of differentially expressed genes shared by the total and newly transcribed fractions gradually decreases with more lenient thresholds of fold-change (Fig. 1C). This result suggests that transcription is mostly responsible for large expression changes in the total mRNA fraction, whereas changes of small magnitude are mainly due to variations of mRNA half-lives. Given the role of miRNAs in fine-tuning expression levels at the post-transcriptional level and the impact of hypoxia on the expression of noncoding RNAs (Choudhry et al. 2014), it is tempting to speculate that the effects of hypoxia on mRNA half-lives could be mediated by miRNAs. Alternatively, this observation may indicate a higher false positive rate when calling differentially expressed genes using lenient thresholds. Finally, we also found genes whose changes in transcription did not correlate with changes in the total RNA fraction. One reason for this discrepancy is that the relative long half-life of mRNAs obscure the detection of changes in transcription by the determination of total expression levels.

Despite the major role of transcription, changes in halflife also contribute to gene regulation by hypoxia. According to our linear model, half-life explains nearly $24 \%$ of the variability on gene expression levels. To identify biological processes associated to genes whose expression was preferentially modulated at the level of transcription or stability, we applied gene set 
enrichment analysis (GSEA) to the list of genes expressed in HUVEC sorted according to their hypoxia-induced change in transcription or decay rates, respectively. We found an enrichment in gene ontology (GO) terms related to metabolism, in particular monosaccharide catabolism, and to response to oxygen levels for genes whose tran- scription was up-regulated in response to hypoxia. However, we could not find any statistically significant overrepresentation of GO-terms for decay-rate sorted genes. In addition, GSEA did not find enrichment of targets of any specific miRNA in the sets of genes whose half-life was decreased by hypoxia. This suggests that
A

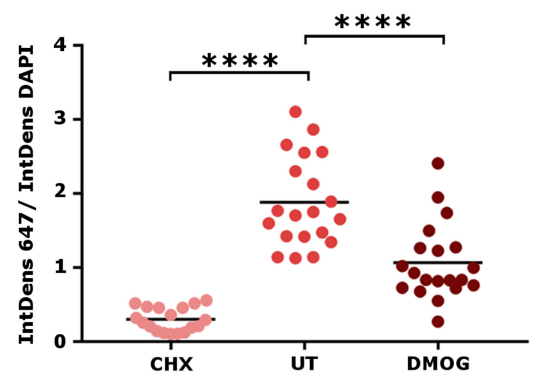

C

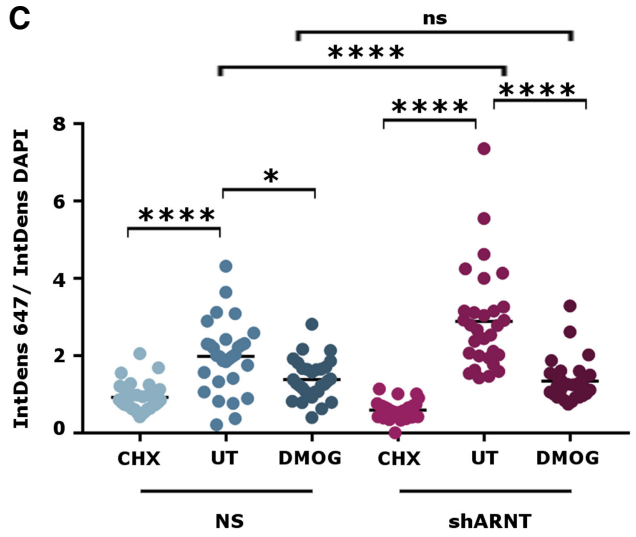

E

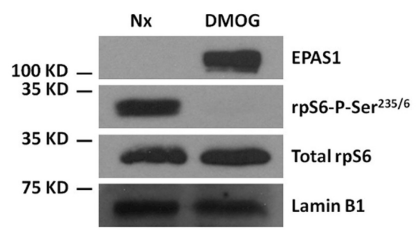

G

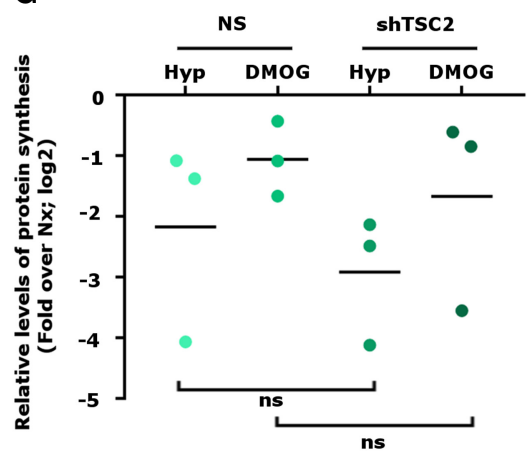

B

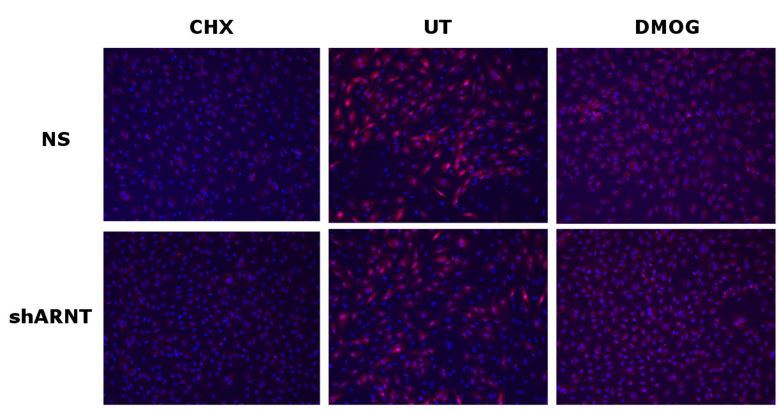

D

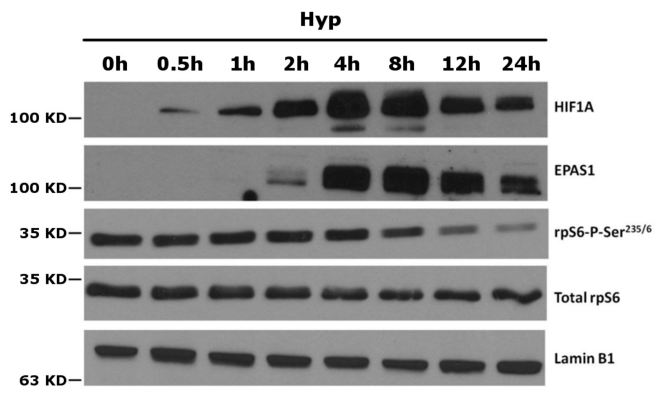

$\mathbf{F}$

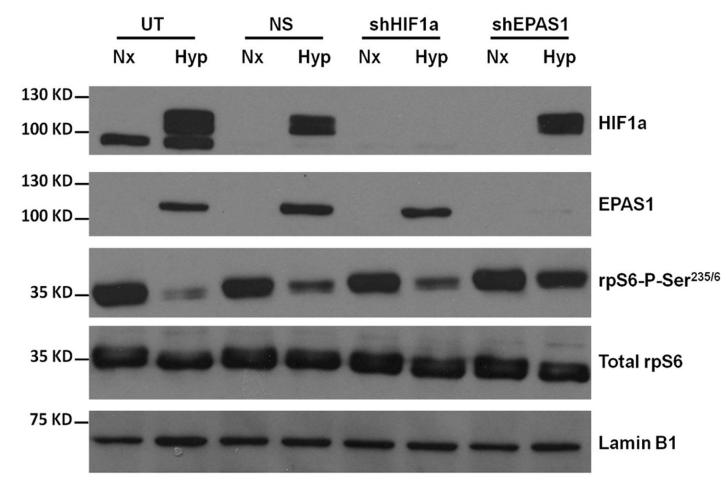

H

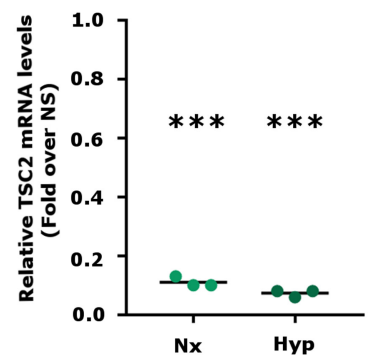

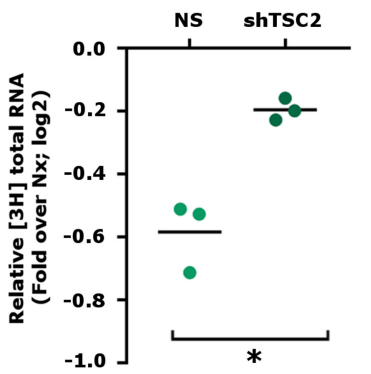

FIGURE 4. (Legend on next page) 
either mRNA decay is controlled by the combined effect of the many independent miRNAs, that are induced by hypoxia (Kulshreshtha et al. 2007; Camps et al. 2014) and the effect of different RNA binding proteins, such as AUBPs, or that it is not mediated by miRNAs. It is important to emphasize that the relative contribution of transcription and stability to the hypoxia-induced changes in mRNA levels vary for individual genes, $72 \%$ and $24 \%$ being the contribution of these two processes on average. Moreover, the increased expression of individual mRNAs can be the result of the coordinated effect of hypoxia on their transcription and decay rates. This is exemplified by VEGFA, a prototypical hypoxia-responsive gene, whose induction involves up-regulation of transcription and decrease of decay rate (Shima et al. 1995; Levy et al. 1996). Changes in VEGFA mRNA stability allow for a fast response to hypoxia; while transcriptional regulation contributes as a later mechanism. On the other hand, the half-life of SLC23A2 (that encodes for the major transporter of ascorbate in endothelial cells) is dramatically reduced under hypoxia from 7.6 to $3 \mathrm{~h}$ (Supplemental Table S1) in parallel with a reduction in its transcription. Interestingly, ascorbate has been described to prevent HIF1A stabilization (Kuiper et al. 2010, 2014), thus the rapid mRNA destabilization of SLC23A2 could facilitate HIF induction under hypoxia.

A potential caveat of our analyses is that our determinations of transcription and decay rates derive from the same $4 \mathrm{sU}$-data sets and thus both variables are not independent, as formally required in multivariate linear regression.
Nonetheless, the concordance of half-live values derived from the 4sU-labeling experiments and those derived from an independent technique based on inhibition of transcription with actinomycin D support the validity of our half-life estimations.

In spite of the relatively minor role of mRNA decay on regulation of gene repression, we found that hypoxia resulted in modest (median reduction of 34\%-36\%) but statistically significant reduction of the overall mRNA stability (Fig. 2A,C). This effect was confirmed by the determination of mRNA decay rates upon transcription inhibition with actinomycin-D (Fig. 2D). We also found that, not only mRNA, but rRNA content per cell was also decreased in hypoxia (Fig. 2E). This result has an important implication, although hypoxia induces the transcription of a large number of miRNAs (Kulshreshtha et al. 2007; Camps et al. 2014), the global effect on both mRNA and rRNA makes miRNAs unlikely mediators of this process, and suggests a general mechanism of RNA degradation rather than a sequence-specific mechanism such as those mediated by miRNAs, in agreement with the result of GSEA mentioned above. In search for a potential mechanism, we found that EGLN/HIF1A-EPAS1 axis was involved in this effect (Fig. 3). Silencing of ARNT, HIF1A or EPAS1 prevented the decrease in RNA content by hypoxia (Fig. 3E,I), while overexpression of active forms of HIF1A and EPAS1 dramatically decrease RNA content per cells (Fig. 3O,P). Thus, this group of experiments suggest that HIF is necessary and sufficient to induce RNA decay in hypoxia. The fact

FIGURE 4. Inactivation of mTOR through TSC2 induces RNA decay in hypoxia. (A) Ratio of the integrated density of the 647 fluorescence divided by the integrated density of the DAPI fluorescence determined by Click-iT Plus OPP Alexa Fluor 647 Protein Synthesis Assay Kit in HUVEC cells grown $16 \mathrm{~h}$ with cycloheximide (CHX), DMOG (DMOG), or untreated (UT). The 647 fluorescence of CHX and DMOG treatment was significantly lower than that of untreated cells (UT) (CHX P-value $<0.0001$, DMOG P-value $<0.0001$. Unpaired Student's t-test). The experiment was repeated in duplicate, a representative experiment is shown. Each dot represents an individual cell. (B) Images of the fluorescence determined by Click-iT Plus OPP Alexa Fluor 647 Protein Synthesis Assay Kit shown in Figure 4C. (C) Ratio of the integrated density of the 647 fluorescence divided by the integrated density of the DAPI fluorescence determined by Click-iT Plus OPP Alexa Fluor 647 Protein Synthesis Assay Kit in HUVEC cells grown 16 $h$ with cycloheximide (CHX), DMOG (DMOG), or untreated (UT). HUVEC cells transduced with lentiviral particles expressing a shRNA to silence ARNT (shARNT) or control shRNA (NS). The 647 fluorescence of CHX and DMOG treatment was significantly lower than that of untreated cells (UT) in both conditions: in shARNT cells and in control cells. ([****] Adjusted $P$-value $<0.0001$; $\left[{ }^{*}\right]$ adjusted $P$-value $=0.0104$, two-way ANOVA followed by Tukey's multiple comparison test). Hypoxia did not have a different effect in cells whose ARNT expression was silenced, compared with the control cells ([ns] adjusted $P$-value > 0.999; two-way ANOVA followed by Tukey's multiple). Each dot represents an individual cell. The graph represents a representative experiment that was performed in duplicate. (D) HUVEC were exposed to hypoxia for the indicated periods of time and the level of HIF1, EPAS1, phospho-S6 Ribosomal Protein (rpS6), total rpS6 and lamin B1 were determined by immunoblot. (E) HUVEC were treated with DMOG (DMOG) or vehicle (Nx) for $16 \mathrm{~h}$ and the levels of phospho-S6 Ribosomal Protein (rpS6), total rpS6 and lamin B1 were determined by immunoblot. (F) HUVEC cells transduced with lentiviral particles expressing a shRNA to silence HIF1A (shHIF1a) or EPAS1 (shEPAS1) expression, a control shRNA (NS) or mock infected (UT) were exposed to normoxia (Nx) or hypoxia (Hyp) for 16 h. The level of HIF1, EPAS1, phospho-S6 Ribosomal Protein (rpS6), total rpS6, and lamin B1 were determined by immunoblot. (G) Ratio of the radioactivity incorporated into proteins precipitated with TCA over total label in cell extracts of hypoxic or DMOG-treated HUVEC cells compared with normoxic extracts. HUVEC cells were transduced with lentiviral particles expressing a shRNA to silence TSC2 (shTSC2) or control shRNA (NS). Each dot represents a single experiment. Silencing of TSC2 expression did not result in any statistical difference with the control cells $(P$-value $=0.1632$ and $P$-value $=0.44$ for Hyp and DMOG treated cells, respectively. Paired Student's t-test). (H) TSC2 mRNA levels in HUVEC cells transduced with lentiviral particles expressing a shRNA to silence TSC2 expression versus control (NS). TSC2 expression was on average $11 \%$ and $7 \%$ of that in control cells in normoxia and hypoxia, respectively, and significantly different to the expected value of 1 (single sample Student's $t$-test, $P<0.0001$ for cells under normoxia and hypoxia). (I) Pulse-labeling of total RNA determined in control HUVEC cells (NS) and cells whose TSC2 expression was silenced (shTSC2). The graph represents the logarithm of the ratio of the hypoxic $(16 \mathrm{~h})$ remaining radioactivity normalized by normoxic values. Each dot represents a determination from a single experiment. The effect of hypoxia on RNA is significantly reduced by silencing TSC2 expression ( $P$-value $=0.0288$; paired Student's $t$-test). 
TABLE 1. Primers used in this study

\begin{tabular}{|c|c|c|c|}
\hline Application & Name & Forward primer & Reverse primer \\
\hline qPCR & ACTB & AAGGCCAACCGCGAGAAG & ACAGCCTGGATAGCAACGTAC \\
\hline qPCR & EGLN3 & ACACGAAGTGCAGCCCTCTT & TCTTCAGCATCAAAGTACCAGACAGT \\
\hline qPCR & VEGFA & ССTTGCTGСTCTACСTCСАС & ATGATTCTGCССTCСTCCTT \\
\hline qPCR & ZNF800 & CACGCCGCAATGAAGAGC & AAGGAGGATCTCCAGGTTCCA \\
\hline qPCR & ZNF281 & ATGACCACCATGGCACTGAG & TCTGGCTTTGGCCTTTTTTGC \\
\hline qPCR & ZNF496 & AGGAAGAGAATGTGCGGGAC & CCCCGTAATCCTCCCCAATG \\
\hline qPCR & POLR3D & CCCTCGGGGGAGTCAAGA & TCTCTGTCCCTTTCACGCTTC \\
\hline qPCR & EHMT1 & GGGAGCCTCAGCAGGATTG & CTTCATCGGCAGCCATAGGT \\
\hline qPCR & TMEM167B & CCGCCGCTATTACCACTGAA & AGCCAGGTTTTGAGACGAGG \\
\hline qPCR & SCYL2 & GGACACTACTCTAGGACCGGG & TTCCAAGCTAGCCCATTGCC \\
\hline qPCR & EID2 & TGCTCCCGGCAGAATACAAG & САСССTGTGAGGATTTCGCT \\
\hline qPCR & TERF2IP & CGGATAGCGGGGAACCAC & AATCAGGAGGGCTCTCATCCA \\
\hline qPCR & DCAF15 & CCGCTACGTCCTCTCCTACA & TCGTCCTGGAATAGCCGAAC \\
\hline qPCR & DCAF16 & СTCTGAGAAGGGAGACGACG & ACTTCAGAGGTGCTTGTTGGAA \\
\hline qPCR & MCM5 & CACGTTGGATGCTGCCTTG & CCGGGTATTTCTGCTTGGTG \\
\hline qPCR & $A C E$ & GTGTGGAACGAGTATGCCGA & GGGTGTGGTTGGCTATTTGC \\
\hline qPCR & PPRC1 & CAGTGGTTGGGGAAGTCGAA & TTCCAGGTCCTTGTCCСTCA \\
\hline qPCR & MCM2 & ATCTACGCCAAGGAGAGGGT & GTAATGGGGATGCTGCCTGT \\
\hline qPCR & MCM3 & AAAGACGGCAGACTCACAGG & GGCGATTCATGCCGATTGAC \\
\hline qPCR & MCM6 & TCCAAGACCTGCCTACCAGA & ACAAGCTCTGGGTGAACTGG \\
\hline qPCR & $D K C 1$ & CGCGGTGCAGGGTAACAT & GGCAATGACTTCCGCTCCTTT \\
\hline qPCR & HMGCS1 & GGCGTCCCACTCCAAATGAT & GGTACTTTCTTGGCAGGGCT \\
\hline qPCR & NOP58 & AAGCATGCAGCTTCTACCGT & GGTTTTGGCTGCCAGCATTC \\
\hline qPCR & PGM1 & AGCTATGAGAAGGACGTTGCC & TGGAGGGACGTACCACATCA \\
\hline qPCR & DNAJB6 & GGACGGGGTCGTTTTTCTCT & GAGAATGAAGTGAGGCCCCC \\
\hline qPCR & HTATIP2 & CCAAAGTCACGCTCATTGGC & GTGGTACCCAGGCAACAGAA \\
\hline qPCR & SEMA6C & AACCACGGATTGCGAACTCA & GGGCTTGAGGGGGATAGGAA \\
\hline qPCR & TMEM44 & TCCTTCGGCCTGTGGATCTG & GGTCCTGTCTGGGTTTCTGT \\
\hline qPCR & ENO2 & TGGCTTTGCCCCCAATATCC & TCTTTTCCGTGTAGCCAGCC \\
\hline qPCR & KLF7 & CAAATGCAACCACTGCGACA & CATGGCAACTCTGGCCTTTC \\
\hline qPCR & NARF & ATCTTCAGACATGCGGCCAA & CAGCAAAGCGTAACACCACC \\
\hline qPCR & P4HA2 & TGGTACAACCTCTTGCGGAG & TTGACATGGGCTGAAGGACC \\
\hline qPCR & CACNB3 & CTAGTGAAAGAGGGCGGGGA & CCGCCTGCTTTTGCTTCTG \\
\hline qPCR & DLG4 & AGCAGGAGTTCACAGAGTGC & CTCGATGACACGCTTCACCT \\
\hline qPCR & ZNF581 & ACACCCAGAGGTCCССТTCT & TCTCAACGGAGGAAAATGCCA \\
\hline qPCR & BNIP3 & GGTCAAGTCGGCCGGAAAAT & TGGAGGTTGTCAGACGCCTT \\
\hline qPCR & ARNT & GAGAATTTCAGGAATAGTGGCCT & CGAGTCTTAGCAGTAGCCTGG \\
\hline qPCR & Pre-RNA & ССTGCTGTTCTCTCGCGCGTCCGAG & AACGCCTGACACGCACGGCACGGAG \\
\hline qPCR & $A D M$ & GGGCTTGGACTTCGGAGTTT & GTACATCAGGGCGACGGAAA \\
\hline qPCR & HIF1A & Hs 00936368 - m1 HIF1A & \\
\hline qPCR & EPAS1 & Hs 01026149 - m1 EPAS1 & \\
\hline
\end{tabular}

that the active HIF isoforms lacking the bHLH motif do not lead to RNA decay together with the dependence on de novo transcription and translation (Fig. 30-O) point to a common target of HIF1A and EPAS1 as an effector for inducing RNA decay whose expression is induced in response to hypoxia.

REDD1 (official name DDIT4) is a target of HIF, and its induction favors the dissociation of TSC2 from the inhibito- ry 14-3-3 proteins, leading to the inhibition of mTOR (Brugarolas et al. 2004; Liu et al. 2006; Deyoung et al. 2008; Wouters and Koritzinsky 2008). Our results show that, in parallel to RNA decay, HUVEC cells inactivate mTOR in a HIF-dependent manner (Figs. 3E, 4F). In addition, silencing of TSC2 prevents RNA decay induced by hypoxia (Fig. 4I), suggesting that the axis EGLN/HIF/ REDD1/TSC2/mTOR regulates RNA stability in hypoxia 
in HUVEC cells. However, we have not formally proved that the effect of HIF on mTOR is mediated through REDD1 and TSC2. In fact, there are other mechanisms by which mTOR is regulated by hypoxia. First, AMP-activated protein kinase (AMPK) regulates mTOR in a HIF-independent way, through TSC1-TSC2 (Liu et al. 2006). Second, the HIFdependent induction of BNIP3 (BCL2/adenovirus E1B 19 $\mathrm{kDa}$ protein-interacting protein 3 ) regulates $\mathrm{mTOR}$ by direct binding to RHEB (Li et al. 2007). In addition, the promyelocytic leukemia tumor suppressor (PML) can bind to mTOR during hypoxia and inactivate it by sequestration in nuclear bodies (Bernardi et al. 2006). Thus, further work will be required to determine the specific candidates that play a role in mTOR inactivation by hypoxia in HUVEC cells.

mTOR has been involved in the suppression of translation during hypoxia (Liu et al. 2006; Wouters and Koritzinsky 2008). However, to our knowledge, it has not been implicated in RNA decay in hypoxia, in spite of the well-documented relation between translation and RNA stability. When mTOR is inactivated, it decreases its serine/threonine kinase activity leading to dephosphorylation of its targets such as S6K and 4E-BP1. 4E-BP1 dephosphorylated sequesters elF4E protein favoring its dissociation from the cap of the mRNAS, inhibiting CAP-dependent translation and leaving the mRNA unprotected. Translation is a highly energy-demanding process that consumes a lot of energy from the cells, thus there are divergent regulatory pathways that converge to ensure the blockage of translation. Additionally to the mTOR axis, there are other mechanisms by which hypoxia regulates translation independently of mTOR such as the regulation of ternary complex availability through the phosphorylation of the alpha subunit of elF2 $\alpha$. This occurs by the unfolded protein response (UPR) in the endoplasmic reticulum in a HIF-independent manner through PERK activation (Koumenis et al. 2002). The existence of these mTOR-independent pathways to block translation can explain why we do not observe a recovery in translation by silencing TSC2 or HIF (Fig. $4 C, G)$. In this context the increased RNA decay in hypoxia, instead of being a mere consequence of the inhibition of translation, could be contributing to the repression of protein synthesis in hypoxia by decreasing mRNA availability.

We observed rRNA degradation in parallel with mRNA degradation in hypoxia that could not be explained just by the dissociation of elF4e (Fig. 2E). An attractive hypothesis is that in hypoxic cells mRNAs that are not being translated, together with the ribosomes, which are no longer needed for the translation of the hypoxic cell, are targeted for degradation; resulting in decreased half-life rates of both mRNA and rRNA. mTOR is fundamental for cell growth and cell survival as it regulates important processes such as mRNA translation, autophagy, or metabolism (Kim and Guan 2019) and has been involved in ribosomal biogenesis (Mayer and Grummt 2006; ladevaia et al. 2012). Thus, mTOR could also regulate rRNA decay. In this regard, it has been described that $S$. cerevisiae treated with rapamycin rapidly decreases its ribosomic content by $40 \%$ to $60 \%$ (Pestov and Shcherbik 2012). In addition, mTOR inhibition also increases ribophagy by random engulfment of cytosolic ribosomes (An and Harper 2018, 2020; Wyant et al. 2018). Thus, mTOR inactivation by hypoxia could mediate rRNA as well as mRNA degradation by hypoxia; however, further work is needed to determine the mechanisms by which mTOR inactivation favors rRNA decay.

In addition to HUVEC, we have also observed decreased RNA content in hypoxia in other types of endothelial cells, such as human microvascular endothelial cells (HMVEC), but not in other cell types like Hela, HEK293T, human fibroblasts or mouse embryonic fibroblasts (data not shown). Thus, RNA degradation could be a specific response of endothelial cells to hypoxia. Alternatively, it could be a general response that is triggered at different hypoxic thresholds depending on the cell type. In agreement, Hepa 1-6 (Johnson et al. 2008), C2C12, and NIH3T3 cells (Mekhail et al. 2006) but not HUVEC, blunt their RNA synthesis in response to very low oxygen concentrations or anoxia. Different cell types could diverge in the mechanisms used to decrease RNA levels in hypoxia to inhibit translation.

In eukaryotes, the majority of mRNAs undergo decay through a pathway that is initiated by the shortening of the poly(A) tail by deadenylases (PAN2-PAN3, CCR4NOT, and PARN).

Therefore, by targeting some of the enzymes that are involved in the RNA-decay machinery, global RNA half-life could potentially be regulated. However, we did not observe hypoxic-induction of any of the genes encoding general RNA turnover proteins or endonucleases. In fact, we found decreased expression of several components of the exosome complex (EXOSC2, EXOSC4, EXOSC6, and EXOSC9) required for general RNA degradation (data not shown). Nevertheless, we cannot rule out that hypoxia alters the protein level or activity of the enzymes involved in general RNA degradation.

In summary, our work supports that transcription is the major determinant of the relative abundance of transcripts in response to hypoxia. Notwithstanding, RNA stability significantly contributes to the changes in gene expression during adaptation to decreased oxygenation. In addition, we also uncovered an unexpected effect of hypoxia on total RNA content, by a EGLN/HIF/TSC2 mediated increase in global decay rates that could potentially contribute to fundamental global responses such as inhibition of translation. Finally, our data provides the first quantitative description of the effects of hypoxia on mRNA half-lives at global scale. 


\section{MATERIALS AND METHODS}

\section{Cell culture and treatments}

Human umbilical vein endothelial cells (HUVEC) from pools of donors were purchased from Lonza (Lonza, C2519A) and grown in Endothelial Medium Bullet Kit (EGM-2, Lonza, CC-3162). For viral production, HEK 293T were maintained in Dulbecco's modified Eagle's medium (Gibco, 41966052) supplemented with 50 $\mathrm{U} / \mathrm{mL}$ penicillin (Gibco, 15140122), $50 \mu \mathrm{g} / \mathrm{mL}$ streptomycin (Gibco, 15140122), 2 mM glutamine (Gibco, 25030123), and $10 \%(v / v)$ fetal bovine serum (Gibco, 10270106). All cells were grown at $37^{\circ} \mathrm{C}$ and $5 \% \mathrm{CO}_{2}$ in a humidified incubator and tested regularly for mycoplasma contamination. For hypoxia treatment, cells were grown at $37^{\circ} \mathrm{C}$ in a $1 \% \mathrm{O}_{2}, 5 \% \mathrm{CO}_{2}, 94 \% \mathrm{~N}_{2}$ gas mixture in a Whitley Hypoxystation H35 (Don Withley Scientific). Alternatively, hypoxic conditions were mimicked using $500 \mu \mathrm{M}$ Dimethyloxalylglycine (DMOG, Sigma, D3695). Actinomycin, cycloheximide, puromycin and rapamycin purchased from Sigma, were used at $5 \mu \mathrm{g} / \mathrm{mL}, 10 \mu \mathrm{g} / \mathrm{mL}, 2 \mu \mathrm{g} / \mathrm{mL}$, and $20 \mathrm{nM}$, respectively.

\section{Metabolic labeling with 4-thiouridine and purification of newly synthesized mRNA}

We used the protocol described by Dolken et al. (2008) and Schwanhausser et al. (2011) that is represented in Figure 1A. Briefly, exponentially growing HUVEC cells were exposed to $21 \%$ (normoxia) or $1 \%$ (hypoxia) oxygen for $8 \mathrm{~h}$ and pulse labeled with 4-thiouridine (400 $\mu \mathrm{M}, 4 \mathrm{sU}$, Sigma, T4509) during the last $2 \mathrm{~h}$ of treatment. After treatment, total cellular RNA was isolated from cells using TRI-reagent (Ambion, AM9738). An amount of $100 \mu \mathrm{g}$ of total RNA was subjected to a biotinylation reaction to label the newly transcribed RNA containing the $4 \mathrm{sU}$ moiety (Pierce, EZ-Link Biotin-HPDP, 21341). Then, RNA was purified using Ultrapure Phenol:Chloroform:Isoamylalcohol (Invitrogen, 15593 031) and labeled RNA was isolated from the total RNA by affinity chromatography using streptavidin coated magnetic beads ( $\mu$ Macs Streptavidin Kit; Miltenyi, 130074 101).

\section{High-throughput sequencing and bioinformatics analysis}

Libraries of total RNA, labeled RNA and unlabeled RNA were prepared using the standard protocol for messenger RNA sequencing (Illumina, TruSeq Stranded mRNA) and sequenced on HiSeq2000 instrument (Illumina) according to the manufacturer's protocol. The resulting reads were aligned to the $\mathrm{GRCh} 37 / \mathrm{hg} 19$ assembly of the human genome using TopHat (Trapnell et al. 2009) with the default parameters. Finally, the gene expression level was calculated as the number of reads per gene, computed using HTSeq (Anders et al. 2015) and gene features as defined in the GRCh37.75 release of the human genome (gtf file). Differential gene expression analysis was performed with the Bioconductor (Gentleman et al. 2004) edgeR package (Robinson et al. 2010) for the R statistical Software (http://www .R-project.org/). The raw reads and processed data derived from RNA-seq experiments published in Tiana et al. (2018) are available at NCBI's Gene Expression Omnibus (Barrett et al.
2009) and are accessible through the GSE89831 GEO Series accession number. All computations were performed using $\mathrm{R}$ software package (http://www.R-project.org/).

\section{mRNA half-life determination}

Individual mRNA half-lives were calculated as described in Dolken et al. (2008). For each mRNA half-life was computed according to the following equation:

$$
t_{1 / 2}=-\frac{t L \times \ln (2)}{\ln \left(1-\frac{e}{a} \times C e\right)},
$$

where $e$ and a represent the amount of newly transcribed RNA and total mRNA, respectively, expressed as the normalized counts from the RNA-seq experiment. $t_{L}$ is the labeling time and $c_{e}$ is a correction factor estimated from slope of the linear regression fit of the $\mathrm{u} / \mathrm{a}$ and e/a values for all the genes expressed in HUVEC according to the formula:

$$
\frac{u}{a}=\frac{1}{C u}-\frac{e}{a} \frac{C e}{C u} .
$$

In this equation $u$ represents the amount of preexisting mRNA expressed as the normalized counts from the RNA-seq experiments. The $\mathrm{Ce}$ and $\mathrm{Cu}$ correction factors can be determined by the estimate of the slope and intercept of the linear fit of the expression level of all three fractions (total, newly transcribed and preexisting). All computations were performed using R software package.

\section{RNA extraction and qPCR}

RNA was extracted and purified using the RNeasy Mini Kit (Qiagen; 74106) following manufacturer's instructions. For quantitative-RT PCR analysis, $1 \mu \mathrm{g}$ of total RNA of each sample was reversed-transcribed to cDNA (Transcriptor First Strand cDNA Synthesis kit, Roche 04379012001), cDNA was diluted 1:20 and used as template for amplification reactions, carried out with the Power SYBR green PCR Master Mix (RNeasy Mini Kit Applied Biosystems; 4367659) following manufacturer's instructions. PCR amplifications were carried out in a StepOne Realtime PCR System (Applied Biosystems; 4376357). Data were analyzed with StepOne software and expression levels were calculated using $\triangle \Delta C T$, using $\beta$-actin as reference. Primers sequences used for qPCR analysis are provided in Table 1. All RT-qPCR data are available in Supplemental Table 3

\section{Individual mRNA half-life calculation using actinomycin $D$}

HUVEC cells were seeded in $6 \mathrm{~cm}^{2}$ plates at a density of $4 \times 10^{5}$ cells/well $8 \mathrm{~h}$ prior to experiments. To determine the effect of hypoxia on mRNA decay rates, cells were exposed to normoxia or hypoxia for $16 \mathrm{~h}$. Then, treated with $5 \mu \mathrm{g} / \mathrm{mL}$ actinomycin D (Sigma; A9415), a general transcription inhibitor, and RNA was isolated $0,1,2,4,8$, and $12 \mathrm{~h}$ after transcription inhibition. Cells were kept at the same oxygen tension for the whole duration of the experiment. The relative amount of specific mRNAs were determined by quantitative RT-PCR. Their decay constant $\left(k_{\text {decay }}\right)$ 
was obtained from the slope of the regression line obtained by the representation of the fraction of mRNA remaining at each time point:

$$
\ln \left(\frac{N_{t}}{N_{0}}\right)=-K_{\text {decay }} \times t
$$

$\mathrm{N}_{\mathrm{t}} / \mathrm{N}_{\mathrm{O}}$ is the remaining fraction of mRNA at time point $t$ after actinomycin $D$ addition. Finally, the half-life for each mRNA was calculated from its decay constant as:

$$
t_{1 / 2}=\frac{\ln (2)}{K_{\text {decay }}}
$$

\section{Pulse-labeling of HUVEC cells with tritiated uridine}

HUVEC cells were seeded in $6 \mathrm{~cm}^{2}$ plates $\left(4 \times 10^{5}\right.$ cells/well) and $8 \mathrm{~h}$ after plating were pulsed for $2 \mathrm{~h}$ with tritiated uridine (Uridine $\left[5,6-{ }^{3} \mathrm{H}\right]$; PerkinElmer; NET367001MC) at final concentration of 2 $\mu \mathrm{Ci} / \mathrm{mL}$. After labeling, cells were washed twice with phosphate buffered-saline (PBS), and incubated in nonradioactive complete culture medium under normoxia or hypoxia for $16 \mathrm{~h}$. The radioactivity present in total RNA fractions was measured using Liquid Scintillation (Optiphase Hisafe II; PerkinElmer, 1200-436) and the Liquid Scintillation Analyzer (PerkinElmer; TriCarb 2800TR).

\section{rRNA synthesis determination}

The determination of the 475 precursor ribosomal RNA (preRNA), was performed by qPCR and normalized by $28 \mathrm{~S}$ using the primers described in Table 1.

\section{Calculation of total RNA and mRNA mass per cell}

HUVEC cells were seeded in $6 \mathrm{~cm}^{2}$ plates at a density of $4.8 \times 10^{5}$ cells per plate and were exposed to normoxia, hypoxia or normoxia in the presence of $500 \mu \mathrm{M}$ DMOG for $16 \mathrm{~h}$. Then DNA and RNA were isolated from each sample and determined by spectrophotometry (NanoDrop ND-1000 instrument, Thermo Scientific). We calculated RNA mass per cell considering that human cells contain $6.6 \mathrm{pg}$ of DNA per cell.

\section{Lentiviral production}

Lentiviral vector pGIPz (Open Biosystems) was used to silence the mRNA expression of ARNT (V3LHS_393533), HIF1A (V2LHS_132150), EPAS1 (V2LHS_113753) and TSC2 (V3LHS_642078), as well as a nonsilencing lentiviral shRNA Control (NS; RHS4346). For the overexpression of HIF mutants stabilized in normoxia, we used PRRL lentiviral vectors containing HIF1A and EPAS1 mutant sequences under cytomegalovirus (CMV) promoter (Kondo et al. 2002). These vectors contain the ODD prolines residues converted to alanine for maintaining HIF constitutively active in normoxic conditions (pRRL-HIF1A-P402A; P564A-IRES-eGFP and pRRL-EPAS1-P405A;P531A-IRES-eGFP). In addition, we used other HIF overexpressing vectors whose bHLH motif had been mutated to prevent DNA-binding (pRRLHIF1A-P402A;P564A-bHLH* -IRES-eGFP and pRRL-EPAS1P405A;P531A-bHLH*-IRES-eGFP). Lentivirus were produced and titrated in HEK293T cells as previously described (Punzon et al. 2004). For transduction of HUVEC cells, lentiviruses were used at a multiplicity of infection (MOI) of 1-2 for $8 \mathrm{~h}$, resulting in more than $95 \%$ transduced (GFP-positive) cells $72 \mathrm{~h}$ after infection.

\section{Western blot}

Cells were harvested in RIPA buffer $(50 \mathrm{mM}$ Tris- $\mathrm{HCl} \mathrm{pH} 8,150$ $\mathrm{mM} \mathrm{NaCl}, 0.02 \% \mathrm{NaN3}, 0,1 \%$ SDS, 1\% NP-40, 1\% Sodium Deoxycholate) containing protease inhibitors (Complete ULTRA tablet; Roche; 06538304001). Protein concentration was quantified using BioRad DC protein assay (BioRad, 5000112) and $40 \mu \mathrm{g}$ of each sample was resolved in 10\% SDS-polyacrilamide gels. Proteins were then transferred to Polyvinylidene difluoride (PVDF) membrane (Immobilon-P, Millipore, IPVH100010). Membranes were blocked with $5 \%$ nonfat dry milk in TBS-T (50 mM Tris- $\mathrm{HCl} \mathrm{pH} \mathrm{7.6,} 150 \mathrm{mM} \mathrm{NaCl}, 0.1 \%$ Tween-20) and incubated with the corresponding antibody (HIF1A: abcam; ab2185; EPAS1: Novus; NB100-122, LaminB1: Santa Cruz, sc-6216, Phospho-S6 Ribosomal Protein [Ser235/236], Cell Signaling, 4858; and S6 Ribosomal Protein, Cell signaling, 2217).

\section{Methionine S-35 pulse-labeling of HUVEC cells}

HUVEC cells were seeded in $6 \mathrm{~cm}^{2}$ plates at a density of $4.8 \times 10^{5}$ cells per plate and exposed to normoxia, hypoxia or normoxia in the presence of $500 \mu \mathrm{M}$ DMOG for $16 \mathrm{~h}$. Then, cells were washed with DMEM lacking methionine and containing $10 \%$ of dialyzed FBS to eliminate the excess of methionine and $25 \mathrm{mM}$ Hepes. Medium was removed and $0.5 \mathrm{ml}$ of DMEM with ${ }^{35} \mathrm{~S}-35$ methionine $(200 \mu \mathrm{Ci} / \mathrm{mL})$ was added, then cells were incubated at $37^{\circ} \mathrm{C} 30 \mathrm{~min}$. Cells were washed with cold PBS and recovered by cell-scrapping and centrifugation and precipitated with $10 \%$ TCA in glass fiber filter disks. To calculate the ratio of TCA-precipitated label relative onto total radioactivity, we measured the amount of radioactivity of each disk by scintillation counting and compared with the total radiolabeled cell suspension fraction obtained before precipitation.

\section{Click-iT Plus OPP Alexa Fluor 647 Protein Synthesis Assay Kit}

HUVEC cells were seeded over coverslips in 24 multiwell plates at a density of 50,000 cells per well, and treated with cycloheximide or DMOG for $16 \mathrm{~h}$. Then we used the Click-iT Plus OPP Alexa Fluor 647 Protein Synthesis Assay Kit following manufacturer's instructions. The analysis of the images was performed by measuring individual cell integrated density of the 647 channel divided by the DAPI integrated density.

\section{SUPPLEMENTAL MATERIAL}

Supplemental material is available for this article.

\section{ACKNOWLEDGMENTS}

This work was supported by Ministerio de Ciencia e Innovación (Spanish Ministry of Science and Innovation, MICINN) 
(SAF2014-53819-R to Luis del Peso and Benilde Jimenez: SAF2017-88771-R to Luis del Peso and Benilde Jimenez).

Received July 5, 2019; accepted April 12, 2020.

\section{REFERENCES}

An H, Harper JW. 2018. Systematic analysis of ribophagy in human cells reveals bystander flux during selective autophagy. Nat Cell Biol 20: 135-143. doi:10.1038/s41556-017-0007-x

An H, Harper JW. 2020. Ribosome abundance control via the ubiquitin-proteasome system and autophagy. J Mol Biol 432: 170-184. doi:10.1016/j.jmb.2019.06.001

Anders S, Pyl PT, Huber W. 2015. HTSeq-a Python framework to work with high-throughput sequencing data. Bioinformatics 31: 166169. doi:10.1093/bioinformatics/btu638

Arany Z, Huang LE, Eckner R, Bhattacharya S, Jiang C, Goldberg MA, Bunn HF, Livingston DM. 1996. An essential role for p300/CBP in the cellular response to hypoxia. Proc Natl Acad Sci 93: 1296912973. doi:10.1073/pnas.93.23.12969

Barrett T, Troup DB, Wilhite SE, Ledoux P, Rudnev D, Evangelista C, Kim IF, Soboleva A, Tomashevsky M, Marshall KA, et al. 2009. NCBI GEO: archive for high-throughput functional genomic data. Nucleic Acids Res 37: D885-D890. doi:10.1093/nar/gkn764

Bernardi R, Guernah I, Jin D, Grisendi S, Alimonti A, TeruyaFeldstein J, Cordon-Cardo C, Celeste Simon M, Rafii S, Pandolfi PP. 2006. PML inhibits HIF- $1 \alpha$ translation and neoangiogenesis through repression of mTOR. Nature 442:779-785. doi:10.1038/nature05029

Brugarolas J, Lei K, Hurley RL, Manning BD, Reiling JH, Hafen E, Witters LA, Ellisen LW, Kaelin WG Jr. 2004. Regulation of mTOR function in response to hypoxia by REDD1 and the TSC1/TSC2 tumor suppressor complex. Genes Dev 18: 2893-2904. doi:10 $.1101 /$ gad.1256804

Camps C, Saini HK, Mole DR, Choudhry H, Reczko M, GuerraAssuncao JA, Tian YM, Buffa FM, Harris AL, Hatzigeorgiou AG, et al. 2014. Integrated analysis of microRNA and mRNA expression and association with HIF binding reveals the complexity of microRNA expression regulation under hypoxia. Mol Cancer 13: 28. doi:10.1186/1476-4598-13-28

Chakraborty $A A$, Laukka T, Myllykoski M, Ringel AE, Booker MA, Tolstorukov MY, Meng YJ, Meier SR, Jennings RB, Creech AL, et al. 2019. Histone demethylase KDM6A directly senses oxygen to control chromatin and cell fate. Science 363: 1217-1222. doi:10.1126/science.aaw1026

Chen $Y$, Zhang $B$, Bao L, Jin L, Yang $M$, Peng $Y$, Kumar A, Wang JE, Wang C, Zou X, et al. 2018. ZMYND8 acetylation mediates HIF-dependent breast cancer progression and metastasis. J Clin Invest 128: 1937-1955. doi:10.1172/JCl95089

Choudhry H, Schodel J, Oikonomopoulos S, Camps C, Grampp S, Harris AL, Ratcliffe PJ, Ragoussis J, Mole DR. 2014. Extensive regulation of the non-coding transcriptome by hypoxia: role of HIF in releasing paused RNApol2. EMBO Rep 15: 70-76. doi:10.1002/ embr.201337642

Cui C, Tseng H. 2004. Estimation of ribosomal RNA transcription rate in situ. BioTechniques 36: 134-138. doi:10.2144/04361RRO4

Czyzyk-Krzeska MF, Dominski Z, Kole R, Millhorn DE. 1994. Hypoxia stimulates binding of a cytoplasmic protein to a pyrimidine-rich sequence in the $3^{\prime}$-untranslated region of rat tyrosine hydroxylase mRNA. J Biol Chem 269: 9940-9945.

Dengler VL, Galbraith MD, Espinosa JM. 2014. Transcriptional regulation by hypoxia inducible factors. Crit Rev Biochem Mol Biol 49: 115. doi:10.3109/10409238.2013.838205
Deyoung MP, Horak P, Sofer A, Sgroi D, Ellisen LW. 2008. Hypoxia regulates TSC1/2-mTOR signaling and tumor suppression through REDD1-mediated 14-3-3 shuttling. Genes Dev 22: 239-251. doi:10.1101/gad.1617608

Dolken L, Ruzsics Z, Radle B, Friedel CC, Zimmer R, Mages J, Hoffmann R, Dickinson P, Forster T, Ghazal P, et al. 2008. High-resolution gene expression profiling for simultaneous kinetic parameter analysis of RNA synthesis and decay. RNA 14: 1959-1972. doi:10.1261/rna.1136108

Elvidge GP, Glenny L, Appelhoff RJ, Ratcliffe PJ, Ragoussis J, Gleadle JM. 2006. Concordant regulation of gene expression by hypoxia and 2-oxoglutarate-dependent dioxygenase inhibition: the role of HIF- $1 \alpha$, HIF- $2 \alpha$, and other pathways. J Biol Chem 281: 15215-15226. doi:10.1074/jbc.M511408200

Galbraith MD, Allen MA, Bensard CL, Wang X, Schwinn MK, Qin B, Long HW, Daniels DL, Hahn WC, Dowell RD, et al. 2013. HIF1A employs CDK8-mediator to stimulate RNAPII elongation in response to hypoxia. Cell 153: 1327-1339. doi:10.1016/j.cell.2013 .04 .048

Galbraith MD, Andrysik Z, Pandey A, Hoh M, Bonner EA, Hill AA, Sullivan KD, Espinosa JM. 2017. CDK8 kinase activity promotes glycolysis. Cell Rep 21: 1495-1506. doi:10.1016/j.celrep.2017 .10 .058

Garneau NL, Wilusz J, Wilusz CJ. 2007. The highways and byways of mRNA decay. Nat Rev Mol Cell Biol 8: 113-126. doi:10.1038/ $n$ rm2104

Gentleman RC, Carey VJ, Bates DM, Bolstad B, Dettling M, Dudoit S, Ellis B, Gautier L, Ge Y, Gentry J, et al. 2004. Bioconductor: open software development for computational biology and bioinformatics. Genome Biol 5: R80. doi:10.1186/gb-2004-5-10-r80

Goldberg MA, Gaut CC, Bunn HF. 1991. Erythropoietin mRNA levels are governed by both the rate of gene transcription and posttranscriptional events. Blood 77: 271-277. doi:10.1182/blood.V77.2 .271 .271

Goldberg-Cohen I, Furneauxb H, Levy AP. 2002. A 40-bp RNA element that mediates stabilization of vascular endothelial growth factor mRNA by HuR. J Biol Chem 277: 13635-13640. doi:10 .1074/jbc.M108703200

Ho V, Acquaviva A, Duh E, Bunn HF. 1995. Use of a marked erythropoietin gene for investigation of its cis-acting elements. J Biol Chem 270: 10084-10090. doi:10.1074/jbc.270.17.10084

Hu CJ, Wang LY, Chodosh LA, Keith B, Simon MC. 2003. Differential roles of hypoxia-inducible factor $1 \alpha(\mathrm{HIF}-1 \alpha)$ and $\mathrm{HIF}-2 \alpha$ in hypoxic gene regulation. Mol Cell Biol 23: 9361-9374. doi:10.1128/MCB .23.24.9361-9374.2003

ladevaia V, Zhang Z, Jan E, Proud CG. 2012. MTOR signaling regulates the processing of pre-rRNA in human cells. Nucleic Acids Res 40: 2527-2539. doi:10.1093/nar/gkr1040

Ivan $\mathrm{M}$, Kondo $\mathrm{K}$, Yang $\mathrm{H}$, Kim W, Valiando J, Ohh $\mathrm{M}$, Salic A, Asara JM, Lane WS, Kaelin WG Jr. 2001. HIF $\alpha$ targeted for VHL-mediated destruction by proline hydroxylation: implications for $\mathrm{O}_{2}$ sensing. Science 292: 464-468. doi:10.1126/science .1059817

lyer N V, Leung SW, Semenza GL. 1998. The human hypoxia-inducible factor $1 \alpha$ gene: HIF1A structure and evolutionary conservation. Genomics 52: 159-165. doi:10.1006/geno.1998.5416

Jaakkola P, Mole DR, Tian YM, Wilson MI, Gielbert J, Gaskell SJ, von Kriegsheim A, Hebestreit HF, Mukherji M, Schofield CJ, et al. 2001. Targeting of HIF- $\alpha$ to the von Hippel-Lindau ubiquitylation complex by $\mathrm{O}_{2}$-regulated prolyl hydroxylation. Science 292: 468-472. doi:10.1126/science.1059796

Jiang BH, Zheng JZ, Leung SW, Roe R, Semenza GL. 1997. Transactivation and inhibitory domains of hypoxia-inducible factor $1 \alpha$. Modulation of transcriptional activity by oxygen tension. J Biol Chem 272: 19253-19260. doi:10.1074/jbc.272.31.19253 
Johnson AB, Denko N, Barton MC. 2008. Hypoxia induces a novel signature of chromatin modifications and global repression of transcription. Mutat Res 640: 174-179. doi:10.1016/j.mrfmmm.2008 01.001

Kasper LH, Boussouar F, Boyd K, Xu W, Biesen M, Rehg J, Baudino TA, Cleveland JL, Brindle PK. 2005. Two transactivation mechanisms cooperate for the bulk of HIF-1-responsive gene expression. EMBO J 24: 3846-3858. doi:10.1038/sj.emboj.7600846

Kim J, Guan KL. 2019. mTOR as a central hub of nutrient signalling and cell growth. Nat Cell Biol 21: 63-71. doi:10.1038/s41556018-0205-1

Kondo K, Klco J, Nakamura E, Lechpammer M, Kaelin WG. 2002. Inhibition of HIF is necessary for tumor suppression by the von Hippel-Lindau protein. Cancer Cell 1: 237-246. doi:10.1016/ S1535-6108(02)00043-0

Koumenis C, Naczki C, Koritzinsky M, Rastani S, Diehl A, Sonenberg N, Koromilas A, Wouters BG. 2002. Regulation of protein synthesis by hypoxia via activation of the endoplasmic reticulum kinase PERK and phosphorylation of the translation initiation factor elF2 $\alpha$. Mol Cell Biol 22: 7405-7416. doi:10.1128/MCB.22 $.21 .7405-7416.2002$

Kuiper C, Molenaar IG, Dachs GU, Currie MJ, Sykes PH, Vissers MC. 2010. Low ascorbate levels are associated with increased hypoxia-inducible factor-1 activity and an aggressive tumor phenotype in endometrial cancer. Cancer Res 70: 5749-5758. doi:10.1158/ 0008-5472.CAN-10-0263

Kuiper C, Dachs GU, Currie MJ, Vissers MC. 2014. Intracellular ascorbate enhances hypoxia-inducible factor (HIF)-hydroxylase activity and preferentially suppresses the HIF-1 transcriptional response. Free Radic Biol Med 69: 308-317. doi:10.1016/j.freeradbiomed .2014 .01 .033

Kulshreshtha R, Ferracin M, Wojcik SE, Garzon R, Alder H, AgostoPerez FJ, Davuluri R, Liu CG, Croce CM, Negrini M, et al. 2007. A microRNA signature of hypoxia. Mol Cell Biol 27: 1859-1867. doi:10.1128/MCB.01395-06

Levy AP. 1998. Hypoxic regulation of VEGF mRNA stability by RNAbinding proteins. Trends Cardiovasc Med 8: 246-250. doi:10 .1016/S1050-1738(98)00020-6

Levy AP, Levy NS, Goldberg MA. 1996. Post-transcriptional regulation of vascular endothelial growth factor by hypoxia. J Biol Chem 271: 2746-2753. doi:10.1074/jbc.271.5.2746

Levy NS, Chung S, Furneaux H, Levy AP. 1998. Hypoxic stabilization of vascular endothelial growth factor mRNA by the RNA-binding protein HuR. J Biol Chem 273: 6417-6423. doi:10.1074/jbc.273.11 .6417

Li Y, Wang Y, Kim E, Beemiller P, Wang CY, Swanson J, You M, Guan KL. 2007. Bnip3 mediates the hypoxia-induced inhibition on mammalian target of rapamycin by interacting with Rheb. J Biol Chem 282: 35803-35813. doi:10.1074/jbc.M705231200

Li JJ, Bickel PJ, Biggin MD. 2014. System wide analyses have underestimated protein abundances and the importance of transcription in mammals. PeerJ 2: e270. doi:10.7717/peerj.270

Liu L, Cash TP, Jones RG, Keith B, Thompson CB, Simon MC. 2006. Hypoxia-induced energy stress regulates mRNA translation and cell growth. Mol Cell 21: 521-531. doi:10.1016/j.molcel.2006.01 .010

Maxwell PH, Wiesener MS, Chang GW, Clifford SC, Vaux EC, Cockman ME, Wykoff CC, Pugh CW, Maher ER, Ratcliffe PJ. 1999. The tumour suppressor protein VHL targets hypoxia-inducible factors for oxygen-dependent proteolysis. Nature 399: 271275. doi:10.1038/20459

Mayer C, Grummt I. 2006. Ribosome biogenesis and cell growth: mTOR coordinates transcription by all three classes of nuclear RNA polymerases. Oncogene 25: 6384-6391. doi:10.1038/sj .onc. 1209883
Mekhail K, Rivero-Lopez L, Khacho M, Lee S. 2006. Restriction of rRNA synthesis by VHL maintains energy equilibrium under hypoxia. Cell Cycle 5: 2401-2413. doi:10.4161/cc.5.20.3387

Mimura I, Nangaku M, Kanki Y, Tsutsumi S, Inoue T, Kohro T, Yamamoto S, Fujita T, Shimamura T, Suehiro J, et al. 2012. Dynamic change of chromatin conformation in response to hypoxia enhances the expression of GLUT3 (SLC2A3) by cooperative interaction of hypoxia-inducible factor 1 and KDM3A. Mol Cell Biol 32: 3018-3032. doi:10.1128/MCB.06643-11

Moreau PR, Örd T, Downes NL, Niskanen H, Bouvy-Liivrand M, Aavik E, Ylä-Herttuala S, Kaikkonen MU. 2018. Transcriptional profiling of hypoxia-regulated non-coding RNAs in human primary endothelial cells. Front Cardiovasc Med 5: 159. doi:10.3389/fcrm .2018.00159

Nallamshetty S, Chan SY, Loscalzo J. 2013. Hypoxia: a master regulator of microRNA biogenesis and activity. Free Radic Biol Med 64: 20-30. doi:10.1016/j.freeradbiomed.2013.05.022

Pestov DG, Shcherbik N. 2012. Rapid cytoplasmic turnover of yeast ribosomes in response to rapamycin inhibition of TOR. Mol Cell Biol 32: 2135-2144. doi:10.1128/MCB.06763-11

Punzon I, Criado LM, Serrano A, Serrano F, Bernad A. 2004. Highly efficient lentiviral-mediated human cytokine transgenesis on the NOD/scid background. Blood 103: 580-582. doi:10.1182/ blood-2003-07-2298

Rabani M, Levin JZ, Fan L, Adiconis X, Raychowdhury R, Garber M, Gnirke A, Nusbaum C, Hacohen N, Friedman N, et al. 2011. Metabolic labeling of RNA uncovers principles of RNA production and degradation dynamics in mammalian cells. Nat Biotechno/ 29: 436-442. doi:10.1038/nbt.1861

Robinson MD, McCarthy DJ, Smyth GK. 2010. edgeR: a Bioconductor package for differential expression analysis of digital gene expression data. Bioinformatics 26: 139-140. doi:10.1093/bioinfor matics/btp616

Rondon IJ, MacMillan LA, Beckman BS, Goldberg MA, Schneider T, Bunn HF, Malter JS. 1991. Hypoxia up-regulates the activity of a novel erythropoietin mRNA binding protein. J Biol Chem 266: 16594-16598.

Salama R, Masson N, Simpson P, Sciesielski LK, Sun M, Tian YM, Ratcliffe PJ, Mole DR. 2015. Heterogeneous Effects of Direct Hypoxia Pathway Activation in Kidney Cancer. PLoS One 10: e0134645. doi:10.1371/journal.pone.0134645

Scheurer SB, Rybak JN, Rosli C, Neri D, Elia G. 2004. Modulation of gene expression by hypoxia in human umbilical cord vein endothelial cells: a transcriptomic and proteomic study. Proteomics 4: 1737-1760. doi:10.1002/pmic.200300689

Schwanhausser B, Busse D, Li N, Dittmar G, Schuchhardt J, Wolf J, Chen W, Selbach M. 2011. Global quantification of mammalian gene expression control. Nature 473: 337-342. doi:10.1038/ nature10098

Schwanhausser B, Busse D, Li N, Dittmar G, Schuchhardt J, Wolf J, Chen W, Selbach M. 2013. Corrigendum: global quantification of mammalian gene expression control. Nature 495: 126-127. doi:10.1038/nature11848

Shih SC, Claffey KP. 1999. Regulation of human vascular endothelial growth factor mRNA stability in hypoxia by heterogeneous nuclear ribonucleoprotein L. J Biol Chem 274: 1359-1365. doi:10.1074/ jbc.274.3.1359

Shima DT, Deutsch U, D'Amore PA. 1995. Hypoxic induction of vascular endothelial growth factor (VEGF) in human epithelial cells is mediated by increases in mRNA stability. FEBS Lett 370: 203-208. doi:10.1016/0014-5793(95)00831-S

Smythies JA, Sun M, Masson N, Salama R, Simpson PD, Murray E, Neumann V, Cockman ME, Choudhry H, Ratcliffe PJ, et al. 2019. Inherent DNA -binding specificities of the HIF $-1 \alpha$ and HIF $-2 \alpha$ 
transcription factors in chromatin. EMBO Rep 20: e46401. doi:10 .15252/embr.201846401

Tiana M, Acosta-lborra B, Puente-Santamaría L, Hernansanz-Agustin P, Worsley-Hunt R, Masson N, García-Rio F, Mole D, Ratcliffe P, Wasserman WW, et al. 2018. The SIN3A histone deacetylase complex is required for a complete transcriptional response to hypoxia. Nucleic Acids Res 46: 120-133. doi:10.1093/nar/gkx951

Trapnell C, Pachter L, Salzberg SL. 2009. TopHat: discovering splice junctions with RNA-Seq. Bioinformatics 25: 1105-1111. doi:10 .1093/bioinformatics/btp120

Voellenkle C, Rooij J, Guffanti A, Brini E, Fasanaro P, Isaia E, Croft L, David M, Capogrossi MC, Moles A, et al. 2012. Deep-sequencing of endothelial cells exposed to hypoxia reveals the complexity of known and novel microRNAs. RNA 18: 472-484. doi:10.1261/ rna.027615.111

Warnecke C, Weidemann A, Volke M, Schietke R, Wu X, Knaup KX, Hackenbeck T, Bernhardt W, Willam C, Eckardt KU, et al. 2008.
The specific contribution of hypoxia-inducible factor-2 $\alpha$ to hypoxic gene expression in vitro is limited and modulated by cell typespecific and exogenous factors. Exp Cell Res 314: 2016-2027. doi:10.1016/j.yexcr.2008.03.003

Weigand JE, Boeckel JN, Gellert P, Dimmeler S. 2012. Hypoxia-induced alternative splicing in endothelial cells. PLoS One 7: e42697. doi:10.1371/journal.pone.0042697

Wouters BG, Koritzinsky M. 2008. Hypoxia signalling through mTOR and the unfolded protein response in cancer. Nat Rev Cancer 8: 851-864. doi:10.1038/nrc2501

Wyant GA, Abu-Remaileh M, Frenkel EM, Laqtom NN, Dharamdasani V, Lewis CA, Chan SH, Heinze I, Ori A, Sabatini DM. 2018. Nufip1 is a ribosome receptor for starvation-induced ribophagy. Science 360: 751-758. doi:10.1126/science.aar2663

Xia X, Kung AL. 2009. Preferential binding of HIF-1 to transcriptionally active loci determines cell-type specific response to hypoxia. Genome Biol 10: R113. doi:10.1186/gb-2009-10-10-r113 

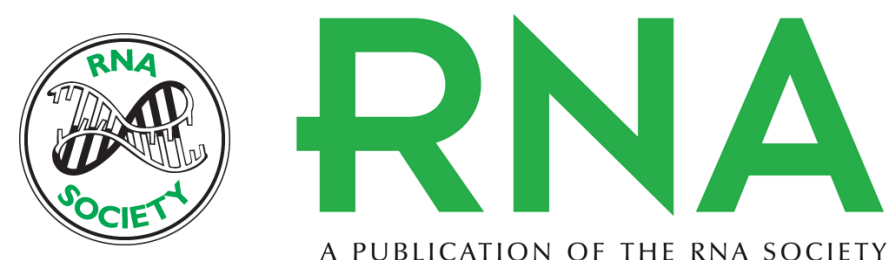

A PUBLICATION OF THE RNA SOCIETY

\section{Metabolic labeling of RNA uncovers the contribution of transcription and decay rates on hypoxia-induced changes in RNA levels}

Maria Tiana, Bárbara Acosta-lborra, Rosana Hernández, et al.

RNA 2020 26: 1006-1022 originally published online April 15, 2020

Access the most recent version at doi:10.1261/rna.072611.119

\section{Supplemental http://rnajournal.cshlp.org/content/suppl/2020/04/15/rna.072611.119.DC1 Material}

References This article cites 70 articles, 27 of which can be accessed free at: http://rnajournal.cshlp.org/content/26/8/1006.full.html\#ref-list-1

Creative This article is distributed exclusively by the RNA Society for the first 12 months after the Commons License full-issue publication date (see http://rnajournal.cshlp.org/site/misc/terms.xhtml). After 12 months, it is available under a Creative Commons License (Attribution-NonCommercial 4.0 International), as described at http://creativecommons.org/licenses/by-nc/4.0/.

Email Alerting
Service

Receive free email alerts when new articles cite this article - sign up in the box at the top right corner of the article or click here.

\section{||||||| Providing Precise Solutions for your research.}

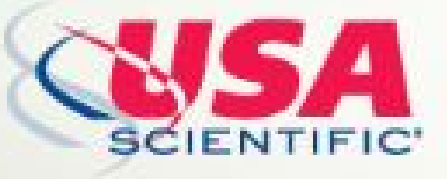

To subscribe to $R N A$ go to:

http://rnajournal.cshlp.org/subscriptions

(C) 2020 Tiana et al.; Published by Cold Spring Harbor Laboratory Press for the RNA Society 